\title{
In situ secondary organic aerosol formation from ambient pine forest air using an oxidation flow reactor
}

\author{
Brett B. Palm ${ }^{1,2}$, Pedro Campuzano-Jost ${ }^{1,2}$, Amber M. Ortega ${ }^{1,3}$, Douglas A. Day ${ }^{1,2}$, Lisa Kaser ${ }^{4,5}$, Werner Jud ${ }^{5}$, \\ Thomas Karl $^{6}$, Armin Hansel ${ }^{5}$, James F. Hunter ${ }^{7}$, Eben S. Cross ${ }^{7}$, Jesse H. Kroll ${ }^{7,8}$, Zhe Peng ${ }^{1,2}$, William H. Brune ${ }^{9}$, \\ and Jose L. Jimenez ${ }^{1,2}$ \\ ${ }^{1}$ Cooperative Institute for Research in Environmental Sciences, University of Colorado, Boulder, CO, USA \\ ${ }^{2}$ Department of Chemistry and Biochemistry, University of Colorado, Boulder, CO, USA \\ ${ }^{3}$ Department of Atmospheric and Oceanic Science, University of Colorado, Boulder, CO, USA \\ ${ }^{4}$ National Center for Atmospheric Research, Boulder, CO, USA \\ ${ }^{5}$ Institute of Ion Physics and Applied Physics, University of Innsbruck, Innsbruck, Austria \\ ${ }^{6}$ Institute of Meteorology and Geophysics, University of Innsbruck, Innsbruck, Austria \\ ${ }^{7}$ Department of Civil and Environmental Engineering, Massachusetts Institute of Technology, Cambridge, MA, USA \\ ${ }^{8}$ Department of Chemical Engineering, Massachusetts Institute of Technology, Cambridge, MA, USA \\ ${ }^{9}$ Department of Meteorology, Pennsylvania State University, State College, PA, USA
}

Correspondence to: Jose L. Jimenez (jose.jimenez@colorado.edu)

Received: 6 October 2015 - Published in Atmos. Chem. Phys. Discuss.: 4 November 2015

Revised: 25 February 2016 - Accepted: 26 February 2016 - Published: 8 March 2016

\begin{abstract}
An oxidation flow reactor (OFR) is a vessel inside which the concentration of a chosen oxidant can be increased for the purpose of studying SOA formation and aging by that oxidant. During the BEACHON-RoMBAS (Bio-hydroatmosphere interactions of Energy, Aerosols, Carbon, $\mathrm{H}_{2} \mathrm{O}$, Organics \& Nitrogen-Rocky Mountain Biogenic Aerosol Study) field campaign, ambient pine forest air was oxidized by $\mathrm{OH}$ radicals in an OFR to measure the amount of SOA that could be formed from the real mix of ambient SOA precursor gases, and how that amount changed with time as precursors changed. High $\mathrm{OH}$ concentrations and short residence times allowed for semicontinuous cycling through a large range of $\mathrm{OH}$ exposures ranging from hours to weeks of equivalent (eq.) atmospheric aging. A simple model is derived and used to account for the relative timescales of condensation of low-volatility organic compounds (LVOCs) onto particles; condensational loss to the walls; and further reaction to produce volatile, non-condensing fragmentation products. More SOA production was observed in the OFR at nighttime (average $3 \mu \mathrm{g} \mathrm{m}^{-3}$ when LVOC fate corrected) compared to daytime (average $0.9 \mu \mathrm{g} \mathrm{m}^{-3}$ when LVOC fate corrected), with maximum formation observed at $0.4-1.5$ eq. days of photochemical aging. SOA formation followed a similar diur-
\end{abstract}

nal pattern to monoterpenes, sesquiterpenes, and toluene $+p$ cymene concentrations, including a substantial increase just after sunrise at 07:00 local time. Higher photochemical aging (> 10 eq. days) led to a decrease in new SOA formation and a loss of preexisting OA due to heterogeneous oxidation followed by fragmentation and volatilization. When comparing two different commonly used methods of $\mathrm{OH}$ production in OFRs (OFR185 and OFR254-70), similar amounts of SOA formation were observed. We recommend the OFR185 mode for future forest studies. Concurrent gas-phase measurements of air after $\mathrm{OH}$ oxidation illustrate the decay of primary VOCs, production of small oxidized organic compounds, and net production at lower ages followed by net consumption of terpenoid oxidation products as photochemical age increased. New particle formation was observed in the reactor after oxidation, especially during times when precursor gas concentrations and SOA formation were largest. Approximately 4.4 times more SOA was formed in the reactor from $\mathrm{OH}$ oxidation than could be explained by the VOCs measured in ambient air. To our knowledge this is the first time that this has been shown when comparing VOC concentrations with SOA formation measured at the same time, rather than comparing measurements made at different times. 
Several recently developed instruments have quantified ambient semivolatile and intermediate-volatility organic compounds (S/IVOCs) that were not detected by a proton transfer reaction time-of-flight mass spectrometer (PTR-TOF-MS). An SOA yield of $18-58 \%$ from those compounds can explain the observed SOA formation. S/IVOCs were the only pool of gas-phase carbon that was large enough to explain the observed SOA formation. This work suggests that these typically unmeasured gases play a substantial role in ambient SOA formation. Our results allow ruling out condensation sticking coefficients much lower than 1 . These measurements help clarify the magnitude of potential SOA formation from $\mathrm{OH}$ oxidation in forested environments and demonstrate methods for interpretation of ambient OFR measurements.

\section{Introduction}

Atmospheric aerosols play a complex and important role in air pollution, human health, and global climate. Exposure to fine particles has adverse effects on cardiopulmonary health (Pope and Dockery, 2006). Aerosols affect climate forcing by directly scattering or absorbing incoming solar radiation. They also act as cloud condensation nuclei $(\mathrm{CCN}$; acronyms are listed in Table 1), affecting the reflectivity, lifetime, and precipitation of clouds (IPCC, 2013). Among all radiative forcings, the estimates for aerosols represent the largest uncertainty (Myhre et al., 2013).

Organic aerosols (OA) make up a substantial fraction of submicron aerosols (Murphy et al., 2006; Zhang et al., 2007; Jimenez et al., 2009). OA is composed of thousands of different molecules, of which only a small fraction has been speciated (Goldstein and Galbally, 2007). OA can be emitted directly in the particle phase as primary OA (POA), or it can be formed as secondary OA (SOA) through gasto-particle conversion. During gas-phase SOA formation, an oxidant (mainly $\mathrm{OH}, \mathrm{O}_{3}$, or $\mathrm{NO}_{3}$ ) reacts with organic gases to produce either less-volatile functionalized products (e.g., reacting to add a hydroxyl group) or more-volatile fragmented products (e.g., breaking $\mathrm{C}-\mathrm{C}$ bonds to produce smaller molecules). If the reaction products have sufficiently lower volatility, they can then partition into the particle phase to form SOA (Pankow, 1994; Donahue et al., 2006). In addition to gas-phase oxidation pathways, SOA formation can result from aqueous chemistry within aerosol water or in cloud droplets (e.g., Lim et al., 2010; Ervens et al., 2011; Ervens, 2015) or heterogeneous uptake reactions (e.g., Surratt et al., 2010). Oxidative aging of gases and particles continues until deposition occurs (or $\mathrm{CO}_{2}$ is produced). The complexity of OA chemistry arises from this intricate mix of multiphase-multigenerational reaction pathways and physicochemical processes involving thousands of molecules.
Table 1. Glossary.

\begin{tabular}{|c|c|}
\hline OFR & Oxidation flow reactor \\
\hline SOA & Secondary organic aerosol \\
\hline LVOC & Low-volatility organic compound \\
\hline $\mathrm{OA}$ & Organic aerosol \\
\hline VOC & Volatile organic compound \\
\hline S/IVOC & $\begin{array}{l}\text { Semivolatile and intermediate-volatility organic } \\
\text { compound }\end{array}$ \\
\hline PTR-TOF-MS & $\begin{array}{l}\text { Proton transfer reaction time-of-flight mass } \\
\text { spectrometer }\end{array}$ \\
\hline $\mathrm{OH}$ & Hydroxyl radical \\
\hline $\mathrm{O}_{3}$ & Ozone \\
\hline $\mathrm{NO}_{3}$ & Nitrate radical \\
\hline MBO & 2-methyl-3-buten-2-ol \\
\hline MT & Monoterpenes \\
\hline SQT & Sesquiterpenes \\
\hline $\mathrm{OHR}_{\text {ext }}$ & External $\mathrm{OH}$ reactivity \\
\hline $\mathrm{OHR}_{\text {int }}$ & Internal $\mathrm{OH}$ reactivity \\
\hline $\mathrm{OH}_{\exp }$ & $\mathrm{OH}$ exposure \\
\hline eq. & Equivalent \\
\hline SMPS & Scanning mobility particle sizer \\
\hline AMS & $\begin{array}{l}\text { Aerodyne High-Resolution Time-of-Flight } \\
\text { Aerosol Mass Spectrometer }\end{array}$ \\
\hline$k_{\mathrm{OH}}$ & Rate constant for reaction with $\mathrm{OH}$ \\
\hline$k_{\mathrm{O}_{3}}$ & Rate constant for reaction with $\mathrm{O}_{3}$ \\
\hline TD-EIMS & $\begin{array}{l}\text { Thermal desorption electron impact mass } \\
\text { spectrometer }\end{array}$ \\
\hline$C^{*}$ & Effective saturation vapor concentration \\
\hline$\tau_{\mathrm{aer}}$ & $\begin{array}{l}\text { Lifetime of LVOCs (or } \mathrm{H}_{2} \mathrm{SO}_{4} \text { ) for } \\
\text { condensation onto aerosols }\end{array}$ \\
\hline$\tau_{\text {wall }}$ & $\begin{array}{l}\text { Lifetime of LVOCs (or } \mathrm{H}_{2} \mathrm{SO}_{4} \text { ) for loss to } \\
\text { OFR walls }\end{array}$ \\
\hline$\tau_{\mathrm{OH}}$ & Lifetime of LVOCs for reaction with $\mathrm{OH}$ \\
\hline$\tau_{\text {total }}$ & Total lifetime for loss of LVOCs (or $\mathrm{H}_{2} \mathrm{SO}_{4}$ ) \\
\hline CS & Condensational sink \\
\hline$D$ & Gas diffusion coefficient \\
\hline$r$ & Particle radius \\
\hline$N(r)$ & Particle number size distribution \\
\hline$\alpha$ & Sticking coefficient \\
\hline Kn & Knudsen number \\
\hline$\lambda_{\mathrm{g}}$ & Mean free path of gas molecules \\
\hline$A / V$ & Surface-area-to-volume ratio of OFR \\
\hline$k_{\mathrm{e}}$ & Coefficient of eddy diffusion \\
\hline$F_{x}$ & $\begin{array}{l}\text { Fraction of LVOCs (or } \mathrm{H}_{2} \mathrm{SO}_{4} \text { ) lost to } \\
\text { pathway } x\end{array}$ \\
\hline $\mathrm{SO}_{4}$ & Sulfate aerosol \\
\hline
\end{tabular}

Much progress has been made in the past decade towards identifying and quantifying the sources, formation, and aging mechanisms of SOA. Aerosol models using traditional (pre-2007) aerosol yields for volatile organic compounds (VOCs) from chamber studies generally underpredict SOA mass by a factor of 10 in urban areas (Volkamer et al., 2006; Hodzic et al., 2010; Hayes et al., 2015). More recent models are able to better predict SOA mass in urban areas by using higher VOC yields and adding previously ignored semivolatile and intermediate-volatility organic compounds (S/IVOCs; Hodzic et al., 2010; Hayes et al., 2015). 
Model comparisons for biogenically dominated areas have not shown such systematic underpredictions even when using older models (e.g., Tunved et al., 2006; Chen et al., 2009; Hodzic et al., 2009; Slowik et al., 2010). Recent measurements of the oxidation of biomass burning emissions, vehicle exhaust, and urban air have also found S/IVOCs to be important contributors to SOA formation (Grieshop et al., 2009; Miracolo et al., 2010; Zhao et al., 2014), building on the ideas of Robinson et al. (2007). However, model parameterizations of SOA formation from S/IVOCs are based on large extrapolations and are still uncertain. The recent AeroCom intercomparison of 31 global OA models showed large variability between models and low temporal correlations between models and measurements (Tsigaridis et al., 2014). Their work suggests that current model parameterizations of SOA formation, transport, and removal processes are inadequate.

SOA formation has traditionally been studied in large environmental "smog" chambers. These chamber experiments have provided the SOA yields for models, but recent evidence shows that chamber experiments are affected by large losses of semivolatile gases to chamber walls (Matsunaga and Ziemann, 2010; Zhang et al., 2014; Krechmer et al., 2015 ) in addition to well-known particle wall losses (Pierce et al., 2008). This is especially true at long (>1 day) residence times, making it difficult to study SOA formation and aging on longer timescales. Also, while chamber experiments have been performed using emissions from mesocosm (e.g., whole tree) systems in the laboratory (e.g., Wyche et al., 2014), it is difficult to perform field experiments with ambient air in chambers (Tanaka et al., 2003). To explore the sources of SOA on a rapid timescale and with a wide range of oxidant exposures, a variety of oxidation flow reactors (OFRs) have been developed (Kang et al., 2007; George et al., 2008; Smith et al., 2009; Keller and Burtscher, 2012). OFRs employ higher oxidant concentrations than chambers while having a short residence time with reduced wall contact. This allows hours to months of equivalent (eq.) atmospheric aging, and the same experimental system can be used in both laboratory and field experiments.

Previous experiments have shown SOA yields from various precursor gases oxidized in an OFR to be similar to yields from large environmental chambers (Kang et al., 2007, 2011; Lambe et al., 2011b, 2015). OFRs have also been used to investigate SOA formation from pollution source emissions containing complex mixtures of precursors such as controlled biomass burning (Ortega et al., 2013; Bruns et al., 2015) and vehicular emissions in a tunnel (Tkacik et al., 2014). Ortega et al. (2015) pioneered the use of an OFR to study SOA formation from ambient air in an urban study in the Los Angeles area. Bruns et al. (2015) found that, for a wood combustion system, the amount of SOA formed in an OFR compared to a large chamber agreed reasonably well. Tkacik et al. (2014) and Ortega et al. (2013) showed substantially more SOA formation than could be explained from speciated VOCs. Despite relying on SOA yields measured in large chambers, which can be affected by the aforementioned wall losses of semivolatile gases, these results suggest that S/IVOCs contribute to SOA formation in biomass burning plumes and vehicle exhaust.

In this study, we used an OFR to expose ambient air to variable levels of $\mathrm{OH}$ in a ponderosa pine forest during the BEACHON-RoMBAS (Bio-hydro-atmosphere interactions of Energy, Aerosols, Carbon, $\mathrm{H}_{2} \mathrm{O}$, Organics \& NitrogenRocky Mountain Biogenic Aerosol Study) campaign. We extensively characterized both the gas and particle phase to investigate the formation and aging of SOA. Changes in aerosol formation with gas precursor concentrations, time of day, and $\mathrm{OH}$ exposure were explored. The fate of condensable organic gases in the OFR was modeled. This model was used to estimate how much SOA formation was missed in the OFR due to gas-phase wall losses, excessive $\mathrm{OH}$ reaction that led to gas-phase fragmentation prior to condensation, and inadequate time/particle surface area for condensation. The SOA mass produced via oxidation was compared to the amount of SOA predicted based on literature yields of measured VOCs. The role of S/IVOCs in SOA formation in a forest was also explored. These results are discussed in the context of improving our knowledge of SOA sources and formation processes in a biogenically dominated environment.

\section{Experimental methods}

\subsection{BEACHON-RoMBAS campaign}

The BEACHON-RoMBAS field campaign (http: //cires.colorado.edu/jimenez-group/wiki/index.php/ BEACHON-RoMBAS) took place at the Manitou Experimental Forest Observatory near Woodland Park, Colorado, in July-August $2011\left(39.10^{\circ} \mathrm{N}, 105.10^{\circ} \mathrm{W} ; 2370 \mathrm{~m}\right.$ elevation). It was a collaboration of 27 institutions from the United States and Europe, focused on understanding primary and secondary biogenic aerosol emissions, formation, and processing. An overview of atmospheric chemistry research at the Manitou Experimental Forest Observatory, including the BEACHON-RoMBAS campaign, has been previously published (Ortega et al., 2014).

The sampling site was located in a ponderosa pine forest in a mountain valley. VOC concentrations were characterized by high 2-methyl-3-buten-2-ol (MBO) during the daytime and monoterpenes (MT) during the nighttime. VOCs at this site have been described in detail for previous campaigns during July-September 2008 (Kim et al., 2010) and August-September 2010 (Kaser et al., 2013a, b), while Fry et al. (2013) discussed diurnal cycles of select biogenic and anthropogenic VOCs during this campaign. The diurnal cycle of the concentration of MBO+isoprene (detected as the same product ion in the proton transfer reaction time-of-flight mass spectrometer: PTR-TOF-MS) measured at an abovecanopy $25 \mathrm{~m}$ inlet ranged from about $1.5 \mathrm{ppb}$ during the day 
to $0.3 \mathrm{ppb}$ at night, while MT concentrations were on average $0.1 \mathrm{ppb}$ during the day and $0.5 \mathrm{ppb}$ at night. The relative ratio of isoprene / $(\mathrm{MBO}+$ isoprene $)$ at this field site was estimated using a combination of GC-MS, PTR-TOF-MS, and whole air sample measurements during summer 2010 (Kaser et al., 2013a) and using $\mathrm{NO}^{+}$ionization mass spectrometry during the BEACHON-RoMBAS campaign (Karl et al., 2012) to be approximately $20 \%$. Isoprene concentrations are calculated in this study using that approximation, which gives values typically < 300 ppt. While largely dominated by biogenic emissions, the site receives some airflow from the front range urban areas (Denver metropolitan area and Colorado Springs) on most days, as evidenced by moderate increases in $\mathrm{NO}_{x}, \mathrm{CO}$, and anthropogenic VOCs during late afternoon and into the evening (Fry et al., 2013; Ortega et al., 2014; Chan et al., 2016).

\subsection{Oxidation flow reactor}

The Potential Aerosol Mass (PAM) oxidation flow reactor (hereafter flow reactor or OFR) is a cylindrical tube $45.7 \mathrm{~cm}$ long with a $19.7 \mathrm{~cm}$ ID and a volume of approximately $13 \mathrm{~L}$, previously described elsewhere (Kang et al., 2007, 2011; Lambe et al., 2011a; Ortega et al., 2013, 2015). Ambient air was sampled through the reactor with a residence time of 2-4 min (3.5-6.5 $\mathrm{L} \mathrm{min}^{-1}$ total flow rate), achieving oxidant exposures of hours to months of eq. atmospheric aging. The $14 \mathrm{~cm}$ diameter inlet plate was removed from the intake end of the OFR to reduce possible losses of semivolatile SOA precursors to the inlet plate inferred in a previous study (Ortega et al., 2013) and to reduce the width of the residence time distribution in the reactor (Ortega et al., 2015). Air was sampled into the reactor through this $14 \mathrm{~cm}$ diameter opening, which was covered with a coarse-grid mesh screen to reduce turbulence in the reactor and prevent insects and debris from entering the reactor. The mesh was coated with an inert silicon coating (Sulfinert by SilcoTek, Bellefonte, PA) to minimize gas and particle losses. OH radicals in the OFR were produced inside the reactor through one of two methods: $\mathrm{OH}$ production from photolysis of ambient $\mathrm{H}_{2} \mathrm{O}, \mathrm{O}_{2}$, and concurrently produced $\mathrm{O}_{3}$ using 185 and $254 \mathrm{~nm}$ light (referred to as the OFR185 method), or $\mathrm{OH}$ production from photolysis of injected (externally produced) $\mathrm{O}_{3}$ using $254 \mathrm{~nm}$ light (referred to as the OFR254 method; Peng et al., 2015a). $\mathrm{O}_{3}$ and $\mathrm{NO}_{3}$ oxidation were also investigated and will be the subject of a future manuscript.
For both methods, UV light was produced using two lowpressure mercury lamps (BHK, Inc., model no. 82-9304-03) mounted inside and on the upper part of the flow reactor. The lamps have discrete emission wavelengths of 185 and $254 \mathrm{~nm}$. The following reactions produce the $\mathrm{OH}$ radicals:

$$
\begin{aligned}
& \mathrm{H}_{2} \mathrm{O}+h v(185 \mathrm{~nm}) \rightarrow \mathrm{OH}+\mathrm{H}, \\
& \mathrm{O}_{2}+h v(185 \mathrm{~nm}) \rightarrow 2 \mathrm{O}\left({ }^{3} \mathrm{P}\right), \\
& \mathrm{O}_{2}+\mathrm{O}\left({ }^{3} \mathrm{P}\right) \rightarrow \mathrm{O}_{3}, \\
& \mathrm{O}_{3}+h v(254 \mathrm{~nm}) \rightarrow \mathrm{O}_{2}+\mathrm{O}\left({ }^{1} \mathrm{D}\right), \\
& \mathrm{O}\left({ }^{1} \mathrm{D}\right)+\mathrm{H}_{2} \mathrm{O} \rightarrow 2 \mathrm{OH} .
\end{aligned}
$$

In the OFR185 method, $\mathrm{OH}$ was produced by $\mathrm{H}_{2} \mathrm{O}$ photolysis (Reaction $\mathrm{R} 1$ ) and also by $\mathrm{O}_{3}$ photolysis (Reactions $\mathrm{R} 4$ and $\mathrm{R} 5$ ), as $\mathrm{O}_{3}$ was formed in the reactor from $\mathrm{O}_{2}$ photolysis (Reactions R2 and R3). In the OFR254 method, the mercury lamps were mounted inside Teflon-coated quartz sheaths, which blocked transmission of $185 \mathrm{~nm}$ light into the OFR, and only Reactions (R4) and (R5) produced $\mathrm{OH}$ by photolysis of injected $\mathrm{O}_{3}$. Following the terminology introduced by Peng et al. (2015a), the method used in this work can be referred to as OFR254-70, signifying that typically 70 ppm of $\mathrm{O}_{3}$ was injected when using the OFR254 method. Note that both wavelengths (185 and $254 \mathrm{~nm}$ ) may initiate chemistry not normally occurring in the troposphere, and $\mathrm{O}\left({ }^{3} \mathrm{P}\right)$ and $\mathrm{O}\left({ }^{1} \mathrm{D}\right)$ are also present in the reactor at elevated concentrations. However, under the OFR conditions of our study neither of those non- $\mathrm{OH}$ reactants is a competitive reaction pathway (Peng et al., 2015b). $\mathrm{O}_{3}$ oxidation, on the other hand, can be competitive in the $\mathrm{OH}$ oxidation experiments under certain conditions. According to Fig. 5 of Peng et al. (2015b), $\mathrm{O}_{3}$ in the OFR185 method during this study likely contributed only a minor $(<20 \%)$ role in the oxidation of a few biogenic VOCs with the largest $k_{\mathrm{O}_{3}} / k_{\mathrm{OH}}$ ratios (e.g., $\beta$-caryophyllene, $\alpha$-terpinene, $\alpha$-humulene), and only at the lowest $\mathrm{OH}$ exposures $\left(\mathrm{OH}_{\mathrm{exp}}\right)$ equivalent to several hours of aging. With the OFR254-70 method, however, the ratio of $\mathrm{O}_{3}$ exposure to $\mathrm{OH}_{\text {exp }}$ was as high as $10^{6}$ for the lowest $\mathrm{OH}_{\exp }$ in this study. Under these conditions, $\mathrm{O}_{3}$ may have played a substantial role in the initial oxidation of a larger number of species of biogenic VOCs (e.g., reacting with $\sim 100 \%$ of $\beta$-caryophyllene and $\alpha$-terpinene, $\sim 60 \%$ of $\alpha$-pinene and limonene, $\sim 20 \%$ of 3 -carene and $\beta$-pinene, $10 \%$ of isoprene). Still, the relative importance of $\mathrm{O}_{3}$ vs. $\mathrm{OH}$ oxidation in the OFR was over an order of magnitude lower than under typical daily-average atmospheric conditions (Peng et al., 2015b).

The $\mathrm{OH}$ exposure was stepped over a range of exposures by adjusting the mercury lamp intensities using programmable computer controls. A key parameter for interpreting the flow reactor aging was the total oxidant exposure, or oxidant concentration integrated over time, experienced by the sampled air. $\mathrm{OH}_{\mathrm{exp}}$ for the OFR185 method was estimated in part based on a model-derived equation, which uses 
measurements of ambient water vapor concentration, $\mathrm{O}_{3}$ produced in the reactor, and estimated external $\mathrm{OH}$ reactivity $\left(\mathrm{OHR}_{\mathrm{ext}}\right)$ as equation parameters ( $\mathrm{Li}$ et al., 2015). $\mathrm{OHR}_{\mathrm{ext}}$ is the $\mathrm{OH}$ reactivity from ambient gases such as VOCs, $\mathrm{CO}$, and $\mathrm{SO}_{2}$, and is accounted for separately from the "internal $\mathrm{OH}$ reactivity ( $\left.\mathrm{OHR}_{\text {int }}\right)$ " from species such as $\mathrm{HO}_{x}, \mathrm{H}_{2} \mathrm{O}_{2}$, and $\mathrm{O}_{3}$ that are greatly enhanced by this reactor. For this study, $\mathrm{OH}_{\text {exp }}$ was calculated using an estimated $\mathrm{OHR}_{\text {ext }}=10 \mathrm{~s}^{-1}$, based on measurements at the same field site and season during previous campaigns (Kim et al., 2013; Nakashima et al., 2014). To provide the best estimate of $\mathrm{OH}_{\exp }$ for this study, the output $\mathrm{OH}_{\exp }$ from the model was divided by a factor of 2 (which is within the estimated model uncertainty of a factor of 3) in order to bring it into better agreement with VOC decay rates measured during this campaign (Sect. 3.2). $\mathrm{OH}_{\mathrm{exp}}$ for the OFR254-70 method was calculated from a different model-derived equation, using $\mathrm{OHR}_{\text {ext }}$ and a measurement of the amount of $\mathrm{O}_{3}$ consumed as equation parameters (Peng et al., 2015a), and was also divided by a factor of 2 . For both methods, $\mathrm{OH}_{\text {exp }}$ was converted to eq. days of atmospheric aging by dividing by a $24 \mathrm{~h}$ average atmospheric concentration of $1.5 \times 10^{6}$ molec $\mathrm{cm}^{-3} \mathrm{OH}$ (Mao et al., 2009). All usage of hours/days of aging in this work refers to eq. ages calculated in this manner.

Oxidant exposure is not the only factor that determines aerosol chemistry. $\mathrm{NO}_{x}$ concentrations have been shown to affect oxidation products and aerosol yields in chamber studies, especially due to the competition of $\mathrm{NO}$ and $\mathrm{HO}_{2} / \mathrm{RO}_{2}$ to react with the $\mathrm{RO}_{2}$ radicals formed during oxidation (e.g., $\mathrm{Ng}$ et al., 2007; Lim and Ziemann, 2009). In all OH oxidation experiments in the reactor, ambient $\mathrm{NO}_{x}$ was rapidly oxidized to $\mathrm{HNO}_{3}$ in as little as a couple of seconds at the highest $\mathrm{OH}$ concentrations, while photolysis of $\mathrm{HNO}_{3}$ back to $\mathrm{NO}_{x}$ was too slow to compete with oxidation ( $\mathrm{Li}$ et al., 2015). Thus, the $\mathrm{OH}$ flow reactor experiments were assumed to occur under $\mathrm{RO}_{2}+\mathrm{HO}_{2}$ conditions.

\subsection{Sampling strategy and measurements}

An important advantage of the OFR technique is that the oxidant concentration inside the reactor can be rapidly and consistently controlled to achieve any desired amount of oxidation from hours up to many weeks of eq. atmospheric age. Stepping through a repeating cycle of several oxidant concentrations from no added $\mathrm{OH}$ to several weeks of eq. aging allowed continuous investigation of SOA formation as a function of this age. The time needed to complete one cycle was kept as short as possible $(\sim 2 \mathrm{~h})$, limited by the number of steps and reactor residence time. This allows the potential of SOA formation from $\mathrm{OH}$ oxidation to be studied over the whole range of exposures as functions of time of day and the concentration of precursors that change on that timescale.

In typical OFR185 and OFR254-70 exposure cycles during BEACHON-RoMBAS, the UV lamps inside the reactor were stepped through six $20 \mathrm{~min}$ long settings of vary- ing lamp intensities for a combined cycle length of $2 \mathrm{~h}$, from both lamps off to both lamps at full intensity. Oxidant and product concentrations in the reactor were allowed $15 \mathrm{~min}$ ( $\sim$ 4-7 reactor residence times) to reach a steady state at each light setting (mainly to allow the OFR to flush, as the lamp UV intensity stabilizes within seconds) before being sampled for the last $5 \mathrm{~min}$ of each cycle. Immediately after this $5 \mathrm{~min}$ sampling period, the lamp intensity was changed to prepare for the next oxidant concentration in the cycle. During the $15 \mathrm{~min}$ in which the OFR was not being sampled, ambient aerosols were sampled directly, through a thermodenuder (Huffman et al., 2008), and directly again, for $5 \mathrm{~min}$ each. In this method, all perturbation measurements (OFR or thermodenuder) are bracketed by unperturbed ambient measurements. The ambient AMS sampling has also been described in Fry et al. (2013).

Ambient aerosols and those after oxidation in the OFR were measured using a TSI 3936 Scanning Mobility Particle Sizer (SMPS) and an Aerodyne High-Resolution Timeof-Flight Aerosol Mass Spectrometer (HR-ToF-AMS, hereafter AMS; DeCarlo et al., 2006). A system of automated valves (Aerodyne AutoValve), controlled by a custom automation program written in Labview (National Instruments, Inc.), was used to multiplex the AMS and SMPS to alternate between measuring ambient air and air oxidized in the OFR (or heated by the thermodenuder). The flow rate through the OFR and all sampling lines was kept constant at all times by using make-up flows when not sampling from each of the inlet lines or reactors. The same custom software was used to control and schedule the UV lamp cycling as well as record relative humidity $(\mathrm{RH})$, temperature, and output $\mathrm{O}_{3}$ concentrations in the OFR. Sampled air was dried to $<30 \%$ RH upstream of the SMPS and AMS, using a Nafion membrane drier (Perma Pure, LLC; MD-110-24S-4). For $\mathrm{OH}_{\exp }$ calculations in the OFR, $\mathrm{O}_{3}$ was measured using a 2B Technologies Model 205 Monitor, and ambient water vapor was measured using a Vaisala HM70 probe. A schematic of the experimental setup is shown in Fig. 1. The SMPS consisted of a TSI 3080 Electrostatic Classifier, a 3081 long Differential Mobility Analyzer (DMA) column, and a 3010 Condensation Particle Counter (CPC). It was operated with sheath and aerosol flow rates of 3.0 and $0.3 \mathrm{~L} \mathrm{~min}^{-1}$, respectively, with a TSI Kr-85 neutralizer and no impactor. The SMPS sampled the range of 14-626 nm mobility diameters, with one $4 \mathrm{~min}$ scan every $5 \mathrm{~min}$, and synchronized with OFR and AMS sampling.

The AMS data used in this analysis were recorded as 2.5 min average mass spectra in "V-mode". Instrument sensitivity was calibrated every 3 days with $400 \mathrm{~nm}$ monodisperse, dried, ammonium nitrate particles. The gas-phase $\mathrm{N}_{2}$ signal, commonly referred to as the air beam, was used to track changes in sensitivity between calibrations. The flow rate of air into the AMS was calibrated in the field before measurements began. A fluorocarbon standard was leaked into the ionization chamber in order to provide high $\mathrm{m} / \mathrm{z}$ back- 


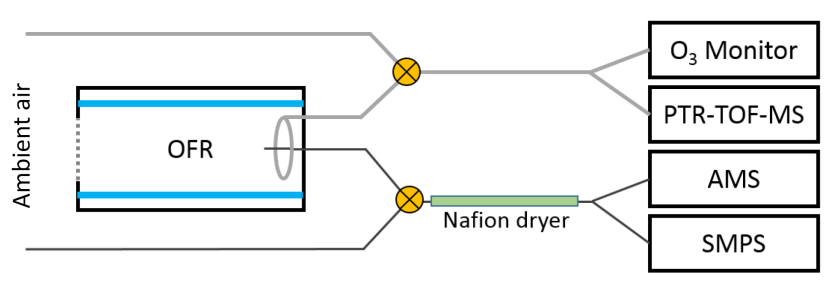

Figure 1. Simplified schematic of the experimental setup. Ambient air was alternately sampled either directly or through the oxidation flow reactor (OFR). In the OFR, the concentration of $\mathrm{OH}$ was increased to simulate atmospheric aging from hours up to several weeks.

ground peaks for improved $m / z$ calibration up to approximately $m / z 300$ (DeCarlo et al., 2006). Corrections were applied to account for gas-phase $\mathrm{CO}_{2}$ interference and water fragmentation patterns using daily aerosol-free background filters and continuous ambient $\mathrm{CO}_{2}$ measurements. AMS and SMPS concentrations and SMPS size distributions were corrected to account for diffusion losses to the walls of the inlet sampling lines, described in Sect. S1 in the Supplement. AMS data were processed using a collection efficiency (CE) of 1, detailed in Sect. S2 and based on a comparison of the AMS and SMPS measurements of ambient aerosol volume (Fig. S2); OFR-oxidized aerosol volume and change in volume (Fig. S3); and total volume enhancement as a function of photochemical age (Fig. S4). AMS concentrations were also corrected for losses of small particles through the aerodynamic lens and to the OFR walls. Details for these corrections can be found in Sect. S3. AMS data are reported at $293 \mathrm{~K}$ and $0.76 \mathrm{~atm}$ (typical ambient values at this research site). The time series, diurnal cycles, and average size distributions of ambient $\mathrm{OA}$, sulfate $\left(\mathrm{SO}_{4}\right)$, nitrate $\left(\mathrm{NO}_{3}\right)$, and ammonium $\left(\mathrm{NH}_{4}\right)$ aerosol mass concentrations have been previously published (Ortega et al., 2014).

While both $\mathrm{OH}$ generation methods detailed above were used during the campaign, the analysis in this paper will mainly focus on the OFR 185 mode for several reasons. The analysis of SOA mass formed vs. predicted in Sect. 3.6 was done using the age range that produced the maximum SOA formation (0.4-1.5 eq. days). However, determination of ages below approximately 1 eq. day using the OFR254-70 method was limited by the ability to accurately measure the amount of injected $\mathrm{O}_{3}$ that was consumed in the reactor. The variability of the measurement of the initial concentration of $\mathrm{O}_{3}$ inside the reactor was approximately $\pm 2 \mathrm{ppm}$ (when reaching a total of about $70 \mathrm{ppm}$ of $\mathrm{O}_{3}$ ) due to variations in the mixing of injected $\mathrm{O}_{3}$ with ambient air sampled into the OFR, especially when sampling in windy conditions. The model used to estimate eq. age for the OFR254-70 method estimated that $2 \mathrm{ppm}$ of photolyzed $\mathrm{O}_{3}$ produced an age of 0.5 eq. days, so that was the effective lower limit of detection of age with the OFR254-70 method under the experimental conditions used during this campaign. Measuring the de- cay of a compound that reacts relatively quickly with $\mathrm{OH}$ but does not react with $\mathrm{O}_{3}$ could allow for better $\mathrm{OH}_{\text {exp }}$ quantification at low ages for OFR254-70. Also, the OFR254 method requires high concentrations of $\mathrm{O}_{3}$ (up to $70 \mathrm{ppm}$ in this study) to be injected in order to reach high ages. As discussed above, $\mathrm{O}_{3}$ may play a role in the oxidation of some VOCs in the OFR254-70 method, while the role of $\mathrm{O}_{3}$ oxidation in OFR185 is minor. This could further complicate the interpretation of the results of $\mathrm{OH}$ oxidation for the lower measurable ages (hours-days) when using OFR254-70. In addition, the temporal data coverage of OFR185 oxidation (23 July4 August, 9-14 and 24-26 August) was much greater than OFR254-70 (17-20 and 28-30 August). This short time period of OFR254-70 measurements combined with the difficulty of sampling at short eq. ages with this particular experimental setup meant that there were few OFR254-70 measurements relative to OFR185 measurements for the analysis in Sect. 3.6. Also, there were no concurrent measurements of S/IVOC concentrations and SOA formation using OFR254-70 available for the analysis in Sect. 3.6.2. If these analyses had been performed on a combined data set using both $\mathrm{OH}$ production methods, the results would have been driven almost completely by OFR 185 measurements. For these reasons, the analyses were performed and conclusions reached using only OFR185 measurements. Regardless, we document below that both $\mathrm{OH}$ oxidation methods gave consistent results for SOA production over the range of overlapping ages $(\sim 1-30$ eq. days) used during this campaign (Sect. 3.4). The time series of OFR 185 and OFR254-70 OA measurements are shown compared to ambient OA, MT, and S/IVOCs in Fig. S7.

This work focuses on the changes in OA mass due to SOA formation and $\mathrm{OA}$ aging as a result of exposure of ambient air to $\mathrm{OH}$. OA enhancement is defined here as the difference between OA mass measured by the AMS after oxidation in the OFR and the average of the two ambient OA concentrations measured just before and after the oxidation data point. If SOA was produced in the reactor, the OA enhancement was positive; if oxidation led to a net loss of OA mass, then the $\mathrm{OA}$ enhancement was negative. As discussed in the results below, SOA formation in the OFR correlated with ambient precursor gas concentrations. If the ambient concentration of those gases was close to 0 , then no SOA formation was observed (e.g., Fig. 8). Therefore, any SOA formation from, e.g., gases desorbing from the OFR walls was negligible.

Measurements of VOCs in ambient air and after OFR oxidation were made using a high-resolution PTR-TOF-MS (Kaser et al., 2013a). This technique can separate and identify isobaric compounds with a mass resolution $(m / \Delta m)$ of up to $\sim 4000$. This allowed for tracking of the depletion of primary biogenic species in the OFR as well as the production of more oxygenated products. Signals from isotopes, internal standards, and possible artifacts (e.g., saturated hydrocarbons that correlate with $\mathrm{O}_{3}$ concentration in the reactor) were removed from the analysis. When calculating pre- 
dicted depletion for $\alpha$-pinene, $\beta$-pinene, 3 -carene, toluene, $p$-cymene, methanol, and sesquiterpenes (SQT; using longifolene as a representative compound) in the subsequent analysis, the following rate constants used were: $k_{\mathrm{OH}}=5.3 \times$ $10^{-11}, 7.7 \times 10^{-11}, 8.7 \times 10^{-11}, 5.5 \times 10^{-12}, 1.5 \times 10^{-11}$, $9.1 \times 10^{-13}$, and $4.8 \times 10^{-11} \mathrm{~cm}^{3}$ molec $^{-1} \mathrm{~s}^{-1}$, respectively (Calvert et al., 2002; Atkinson and Arey, 2003; Alarcón et al., 2014). As an approximation of previous measurements at this site, MT are assumed to be an equal mix of $\alpha$-pinene, $\beta$ pinene, and 3-carene for this analysis (Kim et al., 2010; Ortega et al., 2014). Likewise, the ratio of toluene: $p$-cymene used in calculations was taken from Kaser et al. (2013a) to be $74: 26$. Similar to the multiplexing scheme described above for particle sampling, a system of automated Teflon valves was used to alternate between measuring ambient air and air through the OFR, sampling from the OFR concurrently with the AMS+SMPS. PTR-TOF-MS measurements from the OFR were performed during 1-4 and 24-25 August 2011 while using the OFR185 method. The analysis here focuses on two consecutive sampling cycles from 00:00 to 04:00 MDT (local time) on 3 August 2011, when the concentration of MT was relatively high $(0.8 \mathrm{ppbv})$ and the concentration of $\mathrm{MBO}+$ isoprene was relatively low $(0.1 \mathrm{ppbv})$.

Ambient PTR-TOF-MS measurements are also used in this work to estimate how much SOA could form in the OFR. The continuous PTR-TOF-MS measurements during BEACHON-RoMBAS were made from an inlet at the top of a tower above the canopy at $25 \mathrm{~m}$ height, while the OFR was located on top of an instrument trailer within the canopy at approximately $4 \mathrm{~m}$ height. In-canopy gradients were accounted for by comparing the PTR-TOF-MS measurements at $25 \mathrm{~m}$ with measurements made through the OFR in the absence of oxidant and with measurements from a different nearby inlet at $1 \mathrm{~m}$ height. It was observed that the concentrations of MT, SQT, MBO+isoprene, and toluene $+p$-cymene were approximately $1.9,5.9,1.4$, and 1.2 times higher in the canopy than at $25 \mathrm{~m}$, respectively (discussed in Sect. S4). All analyses in this work were done using estimated in-canopy concentrations, which were inferred by applying these empirical relationships to the continuous $25 \mathrm{~m}$ inlet measurements. This scaling technique has been used before, producing similar results when applied to measurements during the summer 2010 BEACHON-ROCS (BEACHON-Rocky Mountain Organic Carbon Study) campaign at the same field location (Kim et al., 2013; Wolfe et al., 2014).

Ambient $\mathrm{SO}_{2}$ concentrations were measured using a Thermo Environmental Model 43C-TLE analyzer. Data were reported as $5 \mathrm{~min}$ averages from six different heights on a tower up to $25.1 \mathrm{~m}$. We used only data measured at the $5 \mathrm{~m}$ height, to best match the height of the OFR on top of the trailer. The $\mathrm{SO}_{2}$ instrument was automatically zeroed every $6 \mathrm{~h}$, using scrubbed zero grade air. It was calibrated by a standard addition of $3 \mathrm{sccm}$ of a 14 ppmv $\mathrm{SO}_{2}$ in $\mathrm{N}_{2}$ standard (Scott-Marrin) into the 3 standard $\mathrm{L} \mathrm{min}^{-1}$ sample flow.
A novel thermal-desorption electron impact mass spectrometer (TD-EIMS) was used to measure ambient concentrations of ensemble S/IVOCs with volatilities in the range of effective saturation vapor concentrations $\left(C^{*}\right)$ of $10^{1}-10^{7} \mu \mathrm{g} \mathrm{m}^{-3}$. This method involved cryogenic collection of organic gases, temperature-programmed desorption into ultra-high-purity (UHP) helium, and measurement with a high-resolution time-of-flight mass spectrometer (Cross et al., 2013; Hunter et al., 2016). The TD-EIMS provided a time series of the gas-phase organic mass and composition in each volatility bin.

\section{Results and discussion}

\subsection{OFR operation}

Under typical operation, an OFR is used to study oxidation dominated by a single oxidant, similar to typical largechamber experiments. In the case of a field application (as in this study) the sample is a complex and time-varying mixture of ambient precursors that enter the OFR. Importantly, the $\mathrm{OH}: \mathrm{O}_{3}: \mathrm{NO}_{3}$ oxidant ratios produced within the OFR are generally not the same as the changing ambient ratios. Therefore SOA formation in the OFR does not, and is not meant to, reproduce in situ ambient SOA formation at each point in time. In other words, the OFR can be used as a tool to determine the amount of SOA from a single oxidant that would form upon oxidation of ambient gases (both identified and unidentified) at any time of day.

Typical OFR operation of OH oxidation using the OFR185 method is illustrated in Fig. 2, by an example of the evolution of $\mathrm{OA}$ and $\mathrm{SO}_{4}$ aerosol mass concentrations as $\mathrm{OH}$ concentration was cycled through the range of eq. ages. As age increased over the first few lamp settings, OA mass increased due to production and condensation of low-volatility species from the oxidation of gas-phase $\mathrm{SOA}$ precursors. $\mathrm{SO}_{4}$ mass remained nearly the same as in ambient air for these lower ages. The increase of SOA mass at lower ages compared to $\mathrm{SO}_{4}$ is thought to be due to the different rate constants for reaction of $\mathrm{OH}$. The rates with biogenic VOCs, e.g., $k_{\mathrm{OH}}=$ $5.3 \times 10^{-11} \mathrm{~cm}^{3} \mathrm{molec}^{-1} \mathrm{~s}^{-1}$ for $\alpha$-pinene (Atkinson and Arey, 2003), are generally much faster than the reaction of $\mathrm{OH}$ with $\mathrm{SO}_{2}$, where $k_{\mathrm{OH}}=9.49 \times 10^{-13} \mathrm{~cm}^{3}$ molec $^{-1} \mathrm{~s}^{-1}$ (Sander et al., 2011). As the eq. age continued to increase, OA mass enhancement decreased, eventually resulting in net OA loss. These high ages led to a lack of formation of SOA as well as heterogeneous oxidation of the preexisting OA, leading to fragmentation and evaporation (Ortega et al., 2015). The amount of $\mathrm{SO}_{4}$ aerosol production increased with eq. age and plateaued with no further production at ages above $\sim 10$ days. This behavior is consistent with theory, since $\mathrm{SO}_{2}$ has a lifetime of $\sim 8$ days with respect to oxidation by $\mathrm{OH}$ (Sander et al., 2011). Also, as expected, $\mathrm{SO}_{4}$ aerosol (and 


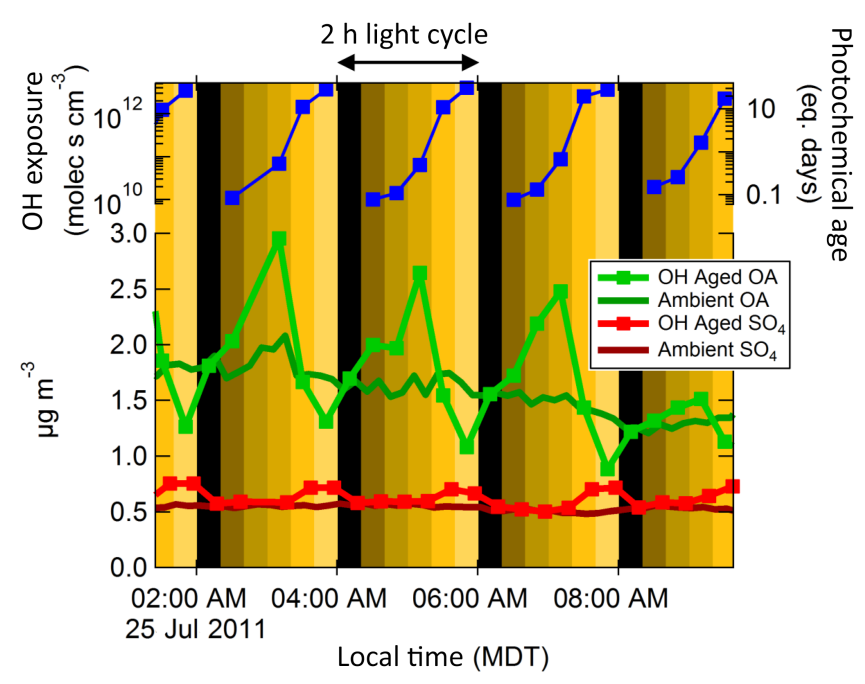

Figure 2. Continuous cycling of $\mathrm{OH}$ oxidation using the OFR 185 method, compared to concurrent ambient measurements. The sawtooth pattern in the OFR results from OA mass enhancement at low-intermediate $\mathrm{OH}$ exposure $\left(\mathrm{OH}_{\mathrm{exp}}\right)$ and decreases at the highest photochemical ages. $\mathrm{SO}_{4}$ mass increased monotonically with $\mathrm{OH}_{\text {exp }}$ and at higher exposures, as expected from relatively slow $\mathrm{SO}_{2}+\mathrm{OH}$ oxidation and lack of $\mathrm{OH}$ destruction of $\mathrm{SO}_{4}$.

$\mathrm{H}_{2} \mathrm{SO}_{4}$ gas) was not consumed by excess $\mathrm{OH}_{\text {exp }}$ in the same way as OA (and SOA precursor gases).

\subsection{VOC enhancement/depletion vs. eq. age}

VOCs were measured before (in ambient air) and after $\mathrm{OH}$ oxidation in the OFR using a PTR-TOF-MS. This showed which VOCs were being depleted, potentially to form SOA, as well as which products were being formed. Also, the decay of VOCs after oxidation provided a direct measurement for validation of the model-derived age estimates. A number of likely compounds have been identified based on measurements from previous campaigns at the Manitou Experimental Forest Observatory site (Kim et al., 2010; Kaser et al., 2013b), as listed in Table 2.

For an overview of PTR-TOF-MS measurements, the difference mass spectrum and mass defect (exact mass minus nominal mass) plots for $4 \mathrm{eq} . \mathrm{h}$ of aging during nighttime are shown in Fig. 3. The greatest absolute magnitude of depletion in oxidized air compared to ambient nighttime air was observed for MT. Depletion was also observed for toluene $+p$-cymene, $\mathrm{MBO}+$ isoprene, $\mathrm{SQT}$, pinonaldehyde + caronaldehyde, and camphor $+\alpha$-pinene oxide. Notably, formation of nopinone was observed after $4 \mathrm{eq}$. $\mathrm{h}$ of aging. $\mathrm{OH}$ oxidation also led to substantial production of several relatively small oxidation product molecules, including formaldehyde, acetaldehyde, formic acid, acetone, and acetic acid, which have been commonly observed in similar photooxidation experiments (e.g., Lee et al., 2006; Ortega et al., 2013). Many other unidentified molecules were observed to be produced in smaller concentrations as a result of $\mathrm{OH}$ oxidation in the flow reactor. A similar plot is shown for higher eq. age (7 days) in Fig. S9, for comparison to Fig. 3. At such a high age, species such as MT, SQT, and toluene $+p$-cymene were completely depleted, while many small oxidation products increased as much as 5 -fold.

In general for all degrees of oxidation, molecules with higher positive mass defects (corresponding to more chemically reduced species such as hydrocarbons) were depleted. Conversely, molecules with lower mass defect (more oxygenated compounds) were formed. This trend is consistent with what would be expected from gas-phase or heterogeneous $\mathrm{OH}$ oxidation chemistry. Also, Fig. 3 shows that monoterpenes constituted the majority of VOCs measured by the PTR-TOF-MS that were depleted after oxidation, while other compounds associated with terpenoid emissions and/or oxidation products were consumed or produced in smaller concentrations.

The relative changes of each of the compounds discussed above are shown as a function of $\mathrm{OH}_{\exp }$ in Fig. 4. As previously discussed, nopinone is an example of a compound that increased in concentration at $4 \mathrm{~h}$ eq. age, indicating that it was an oxidation product in the OFR. This signal showed net formation at low ages (earlier than the peak of maximum SOA formation in the OFR) and eventually decreased to net loss at high exposures, as expected due to its reactivity with $\mathrm{OH}$. Figure 4 also shows the net decay of several other terpene-related species and the formation of smaller, more volatile oxidation products as $\mathrm{OH}_{\text {exp }}$ increased. While the MBO+isoprene signal showed a substantial increase with increasing age, this is likely due to production of an isomeric interference, e.g., a fragment of an oxidation product.

An assessment of the reasonableness of the model-derived $\mathrm{OH}_{\exp }$ (including the factor-of-2 decrease discussed in Sect. 2.2) can be made by comparing the measured depletion of gases vs. expected depletion using published reaction rates with $\mathrm{OH}$. This comparison is shown for an average speciated MT mixture, toluene+ $p$-cymene, and methanol in Fig. 4. The MT and methanol signals decay more slowly than predicted, while the toluene $+p$-cymene signal decays slightly faster. These results are consistent with the previous evaluation of the model-predicted $\mathrm{OH}_{\text {exp }}$ for laboratory and field studies ( $\mathrm{Li}$ et al., 2015). Determination of $\mathrm{OH}_{\text {exp }}$ in the OFR is limited by many factors, including model uncertainties (Peng et al., 2015a), the true non-plug-flow residence time distribution in the OFR, the difficulty of measuring a difference of signals using the PTR-TOF-MS in a perturbed environment, the possibility of competing production of the measured compounds (e.g., methanol), interferences and/or false identification of measured signal (e.g., fragments or different species with the same elemental composition interfering with the measured ions), and uncertainty in the relative composition of the MT and toluene $+p$-cymene mixtures. Despite these uncertainties, the PTR-TOF-MS is clearly measuring formation and decay of compounds that react with $\mathrm{OH}$ on 
Table 2. List of prominent compounds detected by PTR-TOF-MS in the OFR. Likely compound identifications are taken from previous measurements at the same research site, described in Kim et al. (2010) and Kaser et al. (2013b).

\begin{tabular}{llr}
\hline $\begin{array}{l}\text { Protonated molecular } \\
\text { formula }\end{array}$ & Likely compound(s) & Exact mass $(m / z)$ \\
\hline $\mathrm{CH}_{2} \mathrm{O}-\mathrm{H}^{+}$ & Formaldehyde & 31.02 \\
$\mathrm{CH}_{4} \mathrm{O}-\mathrm{H}^{+}$ & Methanol & 33.03 \\
$\mathrm{C}_{2} \mathrm{H}_{4} \mathrm{O}-\mathrm{H}^{+}$ & Acetaldehyde & 45.03 \\
$\mathrm{CH}_{2} \mathrm{O}_{2}-\mathrm{H}^{+}$ & Formic acid & 47.01 \\
$\mathrm{C}_{3} \mathrm{H}_{6} \mathrm{O}-\mathrm{H}^{+}$ & Acetone & 59.05 \\
$\mathrm{C}_{2} \mathrm{H}_{4} \mathrm{O}_{2}-\mathrm{H}^{+}$ & Acetic acid & 61.03 \\
$\mathrm{C}_{5} \mathrm{H}_{8}-\mathrm{H}^{+}$ & MBO $(\sim 80 \%)+$ isoprene $(\sim 20 \%)^{\mathrm{a}}$ & 69.07 \\
$\mathrm{C}_{7} \mathrm{H}_{8}-\mathrm{H}^{+}$ & Toluene(74\%)+p-cymene $(26 \%)^{\mathrm{b}}$ & 93.07 \\
$\mathrm{C}_{10} \mathrm{H}_{14}-\mathrm{H}^{+}$ & p-Cymene & 135.12 \\
$\mathrm{C}_{10} \mathrm{H}_{16}-\mathrm{H}^{+}$ & MT & 137.13 .07 \\
$\mathrm{C}_{9} \mathrm{H}_{14} \mathrm{O}-\mathrm{H}^{+}$ & Nopinone & 139.11 \\
$\mathrm{C}_{10} \mathrm{H}_{14} \mathrm{O}-\mathrm{H}^{+}$ & Pinonaldehyde $\left(-\mathrm{H}_{2} \mathrm{O}\right)$,caronaldehyde $\left(-\mathrm{H}_{2} \mathrm{O}\right)$ & 151.11 \\
$\mathrm{C}_{10} \mathrm{H}_{16} \mathrm{O}-\mathrm{H}^{+}$ & Camphor+ $\alpha$-pinene oxide & 153.13 \\
$\mathrm{C}_{15} \mathrm{H}_{24}-\mathrm{H}^{+}$ & SQT & 205.20 \\
\hline
\end{tabular}

${ }^{\text {a }}$ Karl et al. (2012), Kaser et al. (2013a).

b Kaser et al. (2013a).

the timescale of several hours of photochemical age. This is strong evidence that the OFR can be used to study a wide range of atmospherically relevant timescales.

\subsection{Fate of condensable gases in an OFR}

\subsubsection{Modeled low-volatility organic compound (LVOC) fate}

In order to properly interpret SOA formation as a function of age in an OFR, the timescales of various competing processes need to be carefully considered in the context of the relative importance of those processes in the OFR vs. the atmosphere. When organic gases are oxidized in the OFR, they can form LVOCs, a term used here to describe organic gases with volatilities that are low enough to (effectively) irreversibly condense onto particles or surfaces. In the atmosphere, the dominant fate of these LVOCs is to condense onto aerosols (lifetime of $\sim$ minutes), as dry and wet deposition of even fast-depositing species are generally slower sinks (lifetime of $\sim$ hours; Farmer and Cohen, 2008; Knote et al., 2015; Nguyen et al., 2015). However, due to the different timescales, the LVOCs formed in the OFR can have other fates besides condensation onto aerosols. These include condensational loss to the walls of the OFR, further reaction with $\mathrm{OH}$ to produce either condensable or non-condensable gas-phase products, or exiting the reactor in the gas phase (where they will almost entirely condense on the sampling tube walls, due to the large surface-area-to-volume ratio). If the LVOCs condense onto aerosols, then they are measured by the AMS+SMPS. However, if they are subject to one of the other three fates, then the AMS+SMPS measurements will underestimate the amount of SOA that would form in the atmosphere at the same level of $\mathrm{OH}$ exposure. Similar to loss of gases to large Teflon chamber walls (e.g., Matsunaga and Ziemann, 2010), these other three fates are experimental limitations of the OFR technique that need to be corrected in order to relate OFR measurements to real atmospheric SOA formation processes. As mentioned above, this correction takes into account that dry deposition of such LVOCs is not competitive with condensation onto particles in the atmosphere (Knote et al., 2015; Nguyen et al., 2015). Note that this section pertains to gas-phase losses, while a correction for particle losses to the OFR walls was also included as described in Sect. S3. The need for an LVOC correction to OFR measurements has been suggested before (Lambe et al., 2011a, 2015), but to our knowledge this work is the first attempt to apply one.

In this analysis, we calculate approximate lifetimes of LVOCs for condensation onto aerosols ( $\left.\tau_{\text {aer }}\right)$, loss to the walls of the OFR $\left(\tau_{\text {wall }}\right)$, and reaction with $\mathrm{OH}\left(\tau_{\mathrm{OH}}\right)$ as a function

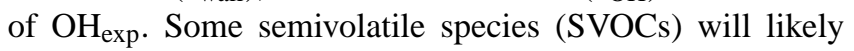
also be produced. However, we focus on irreversibly condensing LVOCs, both for simplicity and based on the observation that most of the OA has low volatility at this site, according to thermal denuder measurements (Hunter et al., 2016) and consistent with measurements at other locations (Cappa and Jimenez, 2010; Lopez-Hilfiker et al., 2016). If the low volatility of OA is a result of condensation of SVOC followed by fast particle-phase reactions to produce lowvolatility species, then the distinction between LVOCs and SVOCs would be irrelevant for this analysis. The lifetimes of LVOCs against different processes are estimated as follows: 


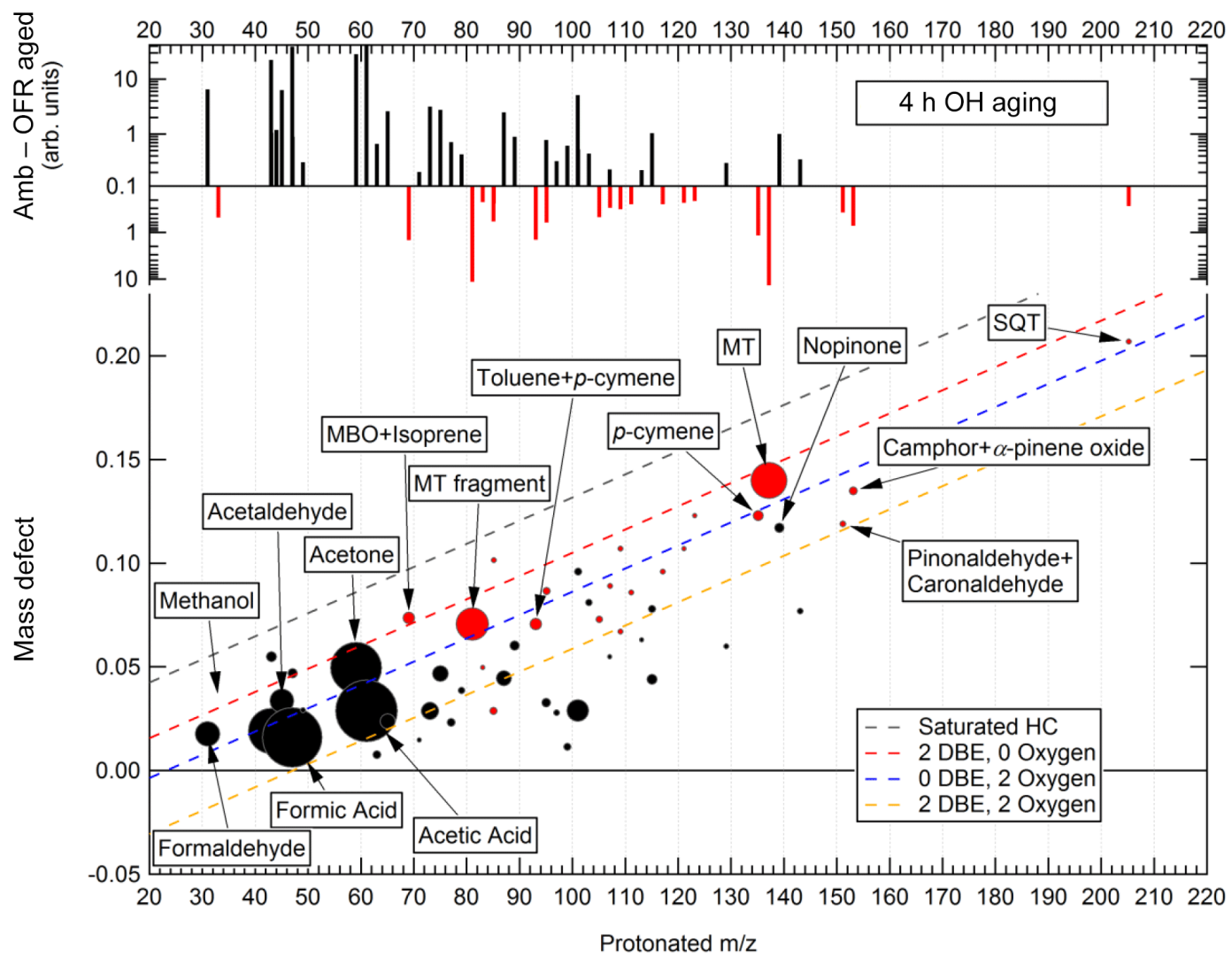

Figure 3. The absolute changes (signal after $\mathrm{OH}$ oxidation in the reactor minus ambient signal) of molecules measured by the PTR-TOF-MS after $4 \mathrm{~h}$ of eq. aging using the OFR185 method, shown as a difference mass spectrum and in a mass defect diagram. The mass spectra are $10 \mathrm{~min}$ averages ( $5 \mathrm{~min}$ from each of the two sample cycles used). The background-subtracted signals are shown in arbitrary units, not corrected for differences in sensitivity of each compound due to the large number of compounds and the inability to positively identify all of them. Prominent molecules are labeled by name or elemental formula assignments. Dashed lines representing molecules with varying double bond equivalents (DBEs) or number of oxygen atoms are shown for reference. A red marker signifies that the signal decreased due to oxidation, while a black marker indicates where signal was greater after oxidation. The markers are sized by the square root of the absolute change in signal at each peak after oxidation (i.e., marker area is proportional to signal). Minor signals with absolute change of $<0.2$ arbitrary units or change of $<20 \%$ of total ambient signal were removed.

- $\tau_{\text {aer }}$ : following Pirjola et al. (1999), the lifetime for LVOC condensation onto aerosols was calculated as

$$
\tau_{\mathrm{aer}}=\frac{1}{4 \pi \cdot \mathrm{CS} \cdot D},
$$

with a diffusion coefficient $D=7 \times 10^{-6} \mathrm{~m}^{2} \mathrm{~s}^{-1}$ being representative of an oxidized organic molecule with a molecular weight of approximately $200 \mathrm{~g} \mathrm{~mol}^{-1}$ at the field site ambient pressure (Tang et al., 2015). CS is the "condensational sink":

$\mathrm{CS}=\int_{0}^{\infty} r \beta(r) N(r) \mathrm{d} r$,

which is the integral of the first moment of the particle size distribution, where $r$ is the wet particle radius, $N(r)$ is the particle number size distribution, and

$$
\beta(r)=\frac{K n+1}{0.377 K n+1+\frac{4}{3} \alpha^{-1} K n^{2}+\frac{4}{3} \alpha^{-1} K n}
$$

is the Fuchs-Sutugin correction for gas diffusion to a particle surface in the transition regime, calculated using the sticking coefficient $\alpha$ of the condensing species (Seinfeld and Pandis, 2006). CS was calculated using the average of the size distributions of ambient air entering the OFR and of air exiting the OFR after oxidation, as a best approximation of the actual CS experienced by LVOCs in the OFR. Since LVOC condensation in the OFR took place under ambient RH, the dried SMPS particle size distribution measurement was corrected to account for the increase in CS from hygroscopic particle growth as a function of RH. For each data point, a 


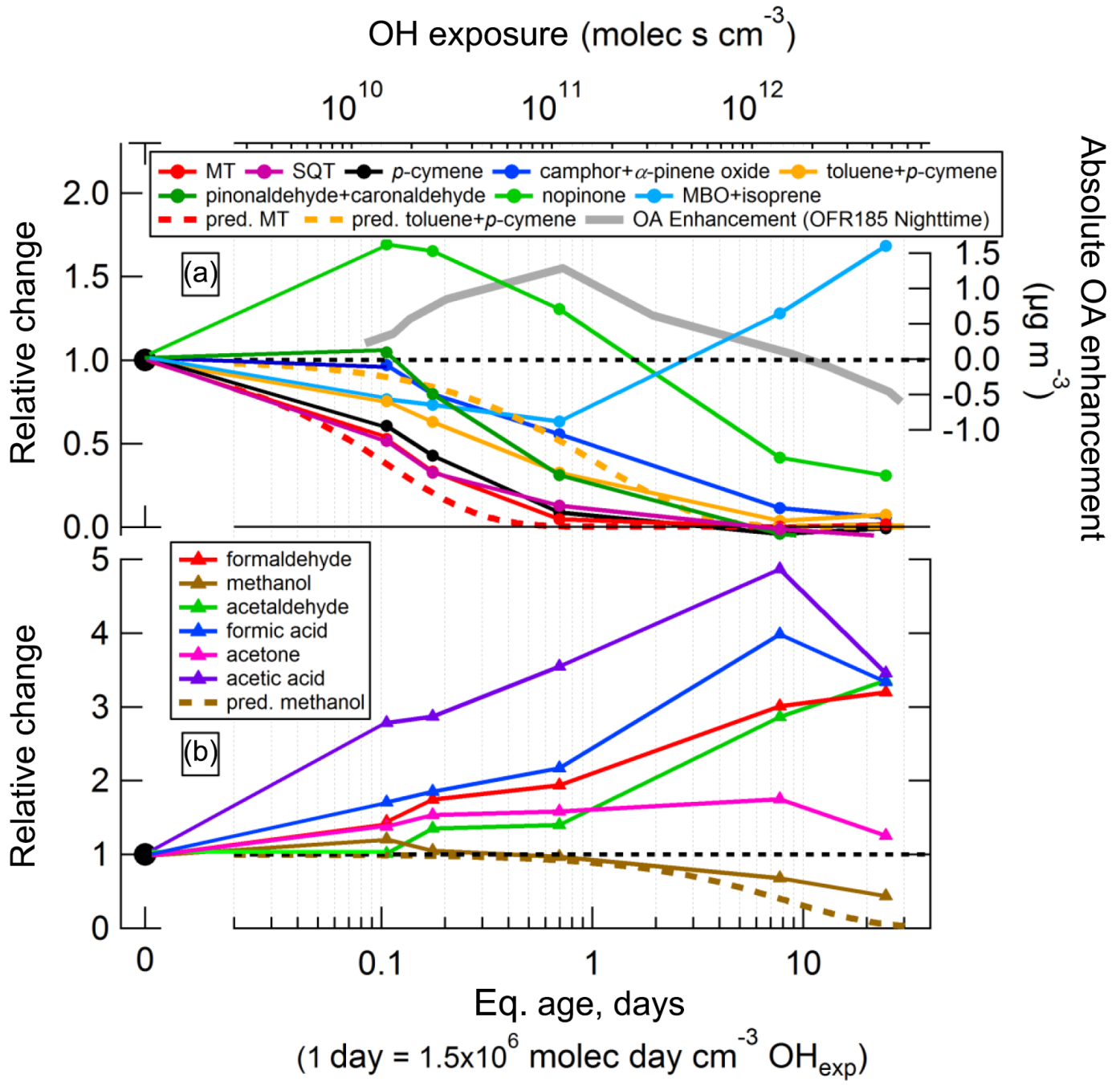

Figure 4. Relative changes in prominent PTR-TOF-MS compounds as a function of photochemical age using the OFR185 method: (a) toluene $+p$-cymene and terpene-related signals compared to nighttime OA enhancement using the OFR185 method (not LVOC fate corrected), and (b) oxidation products formed in the OFR. For comparison, dashed lines indicate theoretical depletion of an equal mix of $\alpha$-pinene, $\beta$-pinene, and 3-carene (the three major MT at this site; Kim et al., 2010; Ortega et al., 2014); a $74: 26$ mix of toluene+ $p$-cymene (Kaser et al., 2013a); and methanol.

growth factor (gf) was calculated from the equation

$\kappa=\sum \varepsilon_{i} \kappa_{i}=\left(\mathrm{gf}^{3}-1\right)\left(1-a_{\mathrm{w}}\right) a_{\mathrm{w}}^{-1}$

from Petters and Kreidenweis (2007) and Nguyen et al. (2015), where $\varepsilon_{i}$ is the volume fraction of aerosol species $i, \kappa_{i}$ is the hygroscopicity parameter of aerosol species $i, \kappa$ is the hygroscopicity parameter of the total aerosol, and $a_{\mathrm{w}}$ is water activity. We approximate $a_{\mathrm{w}}$ as being equal to RH, between 0 and 1 . Total $\kappa$ was estimated using $\kappa_{\mathrm{OA}}=0.13$ as previously reported for this site and campaign (Levin et al., 2014) and $\kappa_{\text {inorganic }}=0.6$, using the volume mixing rule (Petters and Kreidenweis, 2007). The volume fractions were calculated from AMS measurements in ambient air or after OFR oxidation, using estimated component densi- ties (Salcedo et al., 2006; Kuwata et al., 2012). The gf ranged between 1 and 2.3 with an average of 1.2. It was applied to the dry SMPS particle diameter before calculating CS. The correction $\beta(r)$ is a function of the Knudsen number:

$K n=\frac{\lambda \mathrm{g}}{r}$,

where $\lambda_{\mathrm{g}}$ is the mean free path of the condensing gas. Based on previous modeling and measurements, we assume $\alpha=1$ for LVOCs (Kulmala and Wagner, 2001; Julin et al., 2014; Krechmer et al., 2015). A sensitivity study on the values of $D$, the impact of deviations from $\alpha=1$, and the choice of SMPS size distribution used to calculate CS is discussed below in Sect. 3.6.3. 
- $\tau_{\text {wall }}$ : following McMurry and Grosjean (1985), we estimate the first-order rate of LVOC loss to the walls of the OFR limited by eddy diffusion as

$k_{\text {wall }}=\frac{1}{\tau_{\text {wall }}}=\frac{A}{V} \cdot \frac{2}{\pi} \cdot \sqrt{k_{\mathrm{e}} D}$,

which is the version of this equation that is valid when $\alpha$ is sufficiently large (i.e., greater than $\sim 10^{-5}$ ). We used the measured OFR surface-area-to-volume ratio of $A / V=25 \mathrm{~m}^{-1}$ and a coefficient of eddy diffusion $k_{\mathrm{e}}=0.0036 \mathrm{~s}^{-1}$ (much faster than the coefficient $D$ estimated above), estimated by extrapolating values given in McMurry and Grosjean (1985). The choice of $k_{\mathrm{e}}$ is included in the sensitivity analysis in Sect. 3.6.3. Equation (6) results in an estimated wall loss rate of $0.0025 \mathrm{~s}^{-1}\left(\tau_{\mathrm{wall}}=400 \mathrm{~s}\right)$, similar to the lifetime of $\sim 600 \mathrm{~s}$ estimated for this type of OFR in Lambe et al. (2011a). In the absence of any CS and oxidant, an upper limit of approximately $30 \%$ of LVOCs would be lost to the walls and the balance would exit the reactor and be lost to the tubing walls. When including this campaign's average integrated dry particle surface area of $63 \mu \mathrm{m}^{2} \mathrm{~cm}^{-3}$ (with number mode at $\sim 50 \mathrm{~nm}$ ) in the calculation, the percentage lost to the walls decreases by only a few percent to $26 \%$. If using an integrated particle surface area of $500 \mathrm{\mu m}^{2} \mathrm{~cm}^{-3}$ that might be found in an urban, pollution source, or lab study, the percentage drops to $15 \%$.

- $\tau_{\mathrm{OH}}$ : to estimate the loss of LVOCs to non-condensable products due to continued reaction with $\mathrm{OH}, \tau_{\mathrm{OH}}$, we make the assumption that LVOCs will remain available to condense on aerosols or walls, or to exit the reactor for up to five generations of $\mathrm{OH}$ reaction. After they have reacted five times with $\mathrm{OH}$, they are deemed lost by fragmentation into small oxidized molecules that are too volatile to condense. Further, we assume a rate constant for reaction with $\mathrm{OH}$ (on the order of that for an oxygenated molecule with 10 carbon atoms and no $\mathrm{C}=\mathrm{C}$ double bonds) of $k_{\mathrm{OH}}=1 \times$ $10^{-11} \mathrm{~cm}^{3} \mathrm{molec}^{-1} \mathrm{~s}^{-1}$ (Ziemann and Atkinson, 2012), so

$$
\tau_{\mathrm{OH}}=\frac{5}{k_{\mathrm{OH}} \cdot[\mathrm{OH}]} .
$$

Sensitivity studies for variations in parameters $k_{\mathrm{OH}}$ and the number of reactions with $\mathrm{OH}$ before LVOCs fragment to noncondensable products are also discussed in Sect. 3.6.3.

These three lifetimes are combined to determine the total lifetime of loss of LVOCs to these three combined pathways:

$\tau_{\text {total }}=\left(\frac{1}{\tau_{\mathrm{aer}}}+\frac{1}{\tau_{\mathrm{wall}}}+\frac{1}{\tau_{\mathrm{OH}}}\right)^{-1}$.

This total lifetime is compared to the average OFR residence time $\tau_{\mathrm{OFR}}$ (OFR volume divided by flow rate) to determine the fraction of LVOCs that exits the OFR without reaching one of the three other fates (and thus condenses onto sampling line walls):

$F_{\text {exit }}=e^{\frac{-\tau_{\text {OFR }}}{\tau_{\text {total }}}}$.

The fraction of LVOCs that is lost to each pathway inside the OFR is then

$F_{x}=\left(1-F_{\text {exit }}\right) \cdot\left(\frac{k_{x}}{k_{\text {total }}}\right)$,

where the rate constant $k_{x}=\tau_{x}^{-1}$ and $x=$ wall, $\mathrm{OH}$, or aerosol (aer).

Figure 5c compares all of the LVOC lifetimes and fractional fates as a function of age and $\mathrm{OH}_{\text {exp }}$, with a typical OFR residence time of $140 \mathrm{~s}$ shown for comparison. The fractional fates are shown using high (Fig. 5a) and low (Fig. 5b) rates of condensation to aerosol, based on typical higher and lower aerosol surface areas during this particular campaign. As discussed below (Sect. 3.5), $\mathrm{OH}$ oxidation leads to a substantial increase in the number of small particles when gas-phase precursors are available. This in turn increases the surface area available for condensation of LVOCs, and therefore $\tau_{\text {aer }}$ depends on the amount of SOA formed from $\mathrm{OH}$ oxidation in the OFR in addition to the ambient particle surface area. During times of low SOA formation $\left(<0.3 \mu \mathrm{g} \mathrm{m}^{-3}\right)$, total dry surface area concentrations after oxidation are similar to ambient concentrations in the range of $30-100 \mu \mathrm{m}^{2} \mathrm{~cm}^{-3}$, and $\tau_{\text {aer }}$ is estimated to be approximately $400 \mathrm{~s}$ or longer. However, during times with $>1.5 \mu \mathrm{g} \mathrm{m}^{-3}$ SOA formation, total dry surface area concentrations increase to $100-400 \mu \mathrm{m}^{2} \mathrm{~cm}^{-3}$ or larger and $\tau_{\text {aer }}$ becomes $<100 \mathrm{~s}$.

For an eq. age of 0.1 day, as little as $20 \%$ of the LVOCs formed in the OFR are predicted to condense onto aerosols, with the rest being lost to the walls in or after the OFR. However, the majority of LVOCs are likely not produced until higher $\mathrm{OH}_{\text {exp }}$, concurrent with the highest SOA production. As eq. age increases into the $0.2-3$ day range, condensation onto aerosols can account for as much as $75 \%$ of LVOC fate, provided there is enough SOA formation to sufficiently increase the total particle surface area. In this case, shown in Fig. 5a, the remaining $25 \%$ of LVOCs are approximately equally split between loss to the walls, exiting the OFR, and reacting with $\mathrm{OH}$ more than five times. However if sufficient particle surface area is not formed, as in Fig. 5b, then still only $20 \%$ of LVOCs will condense onto aerosols.

For the conditions analyzed here from the BEACHONRoMBAS campaign, these calculations suggest that, when there were enough gas-phase precursors to produce $>1.5 \mu \mathrm{g} \mathrm{m}^{-3} \mathrm{SOA}$, it is likely that the majority of this aerosol (up to $\sim 75 \%$ ) would be produced and measured in the OFR despite the perturbed timescales. When there were relatively few gas-phase precursors and little SOA was formed, it is likely that a majority of the LVOCs were not able to condense 


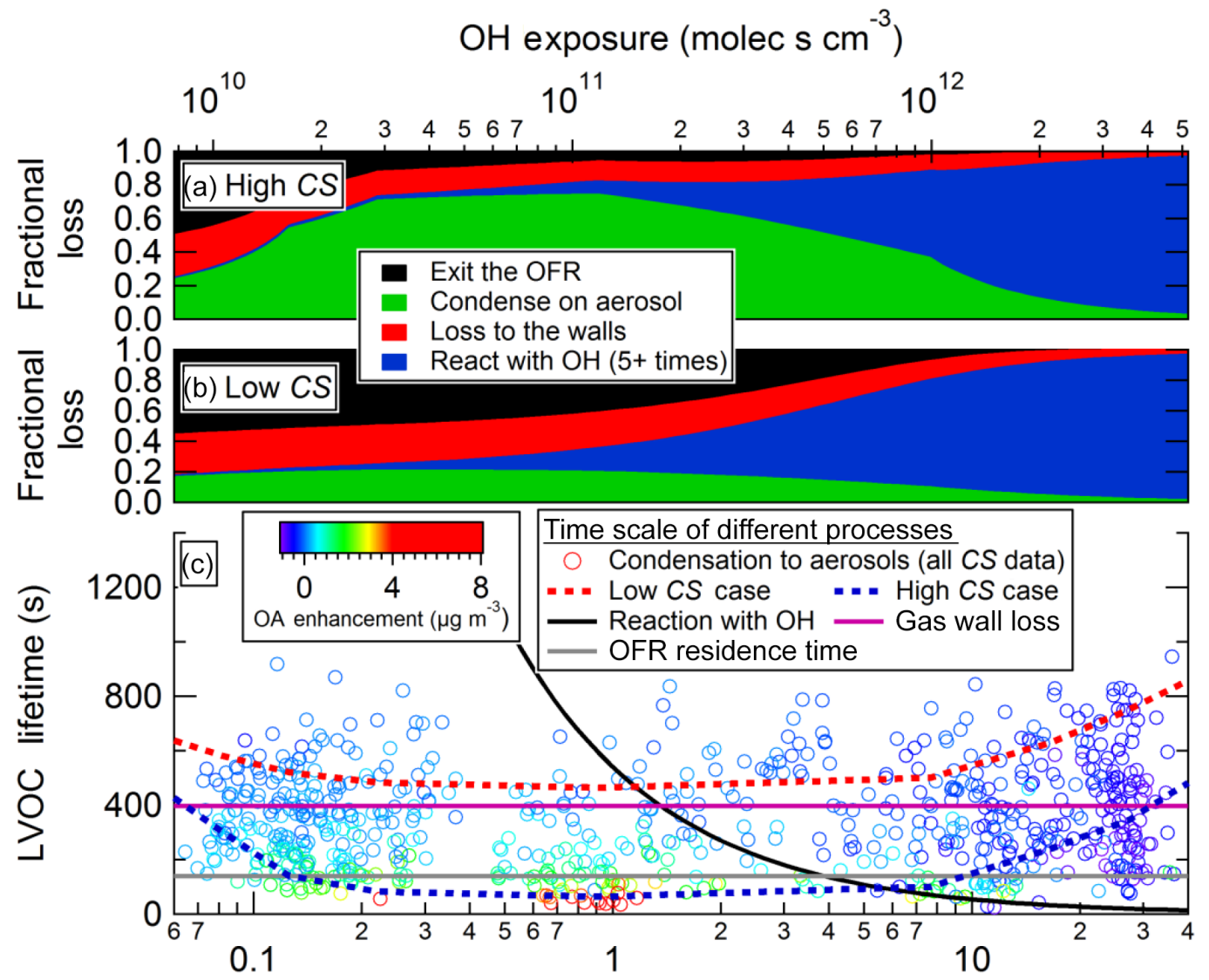

$$
\begin{gathered}
\text { Eq. age, days } \\
\left(1 \text { day }=1.5 \times 10^{6} \text { molec day } \mathrm{cm}^{-3} \mathrm{OH}_{\text {exp }}\right)
\end{gathered}
$$

Figure 5. Fractional fates of loss of LVOCs to OFR walls, condensation to aerosols, reaction with OH to produce volatile products, or exiting the OFR to be lost on sampling line walls as a function of photochemical age for (a) high-CS and (b) low-CS cases; (c) LVOC lifetimes for each of these pathways. Lifetime for condensation to aerosols is shown for all data points (colored by OA enhancement after oxidation) using CS calculated from SMPS measurements.

into SOA during the reactor residence time. However, if there were few precursors to begin with, the absolute amount of potential SOA mass that would not have time to condense would still be relatively small, limiting the effect of this correction on the objectives of this study.

Another important conclusion from this analysis is that for high eq. ages $>10$ days, a very small fraction of the LVOCs formed $(<10 \%)$ will condense to form new SOA. The remainder will react many times with $\mathrm{OH}$ before having a chance to condense, likely leading to smaller fragmentation products that are too volatile to condense into SOA. This is, of course, different from what occurs in the atmosphere, where LVOCs would typically have sufficient time for condensation to aerosols under most conditions. Since this rapid oxidation will remove any semivolatile vapors from the gas phase, semivolatile OA molecules will begin to evaporate to reestablish equilibrium partitioning. However, measure- ments of evaporation kinetics for ambient and lab-generated SOA suggest that evaporation is too slow to account for the changes measured during the short OFR residence time (Vaden et al., 2011). Furthermore, thermodenuder measurements have shown that only a small fraction $(\sim 20 \%)$ of ambient OA would be susceptible to evaporation due to removal of the gas-phase molecules (Cappa and Jimenez, 2010; Ortega et al., 2015). Therefore, heterogeneous oxidation of the preexisting $\mathrm{OA}$ by $\mathrm{OH}$ likely dominates the measured $\mathrm{OA}$ depletion at very high eq. ages (DeCarlo et al., 2008; Ortega et al., 2015).

\subsubsection{Model validation: sulfuric acid $\left(\mathrm{H}_{2} \mathrm{SO}_{4}\right)$ condensation}

In addition to LVOCs, $\mathrm{H}_{2} \mathrm{SO}_{4}$ can also be produced in the OFR from $\mathrm{OH}$ oxidation of $\mathrm{SO}_{2} \cdot \mathrm{H}_{2} \mathrm{SO}_{4}$ molecules can also condense onto OFR or sampling line walls (but not be lost 


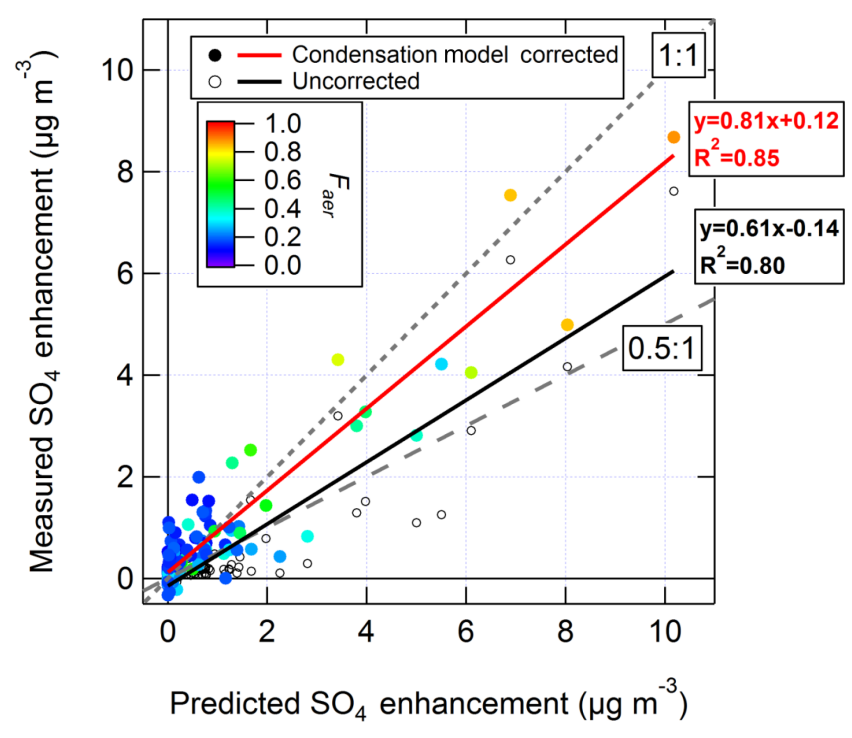

Figure 6. Measured vs. predicted $\mathrm{SO}_{4}$ formation after $\mathrm{OH}$ oxidation in an OFR. The data points are colored by the fraction of $\mathrm{H}_{2} \mathrm{SO}_{4}$ predicted to condense on aerosols, calculated using $\alpha=0.65$ and the average of the SMPS size distributions measured before and after oxidation. Data are shown with the LVOC fate correction applied, along with linear fits to the corrected (red) and uncorrected (black) data. Ambient $\mathrm{SO}_{2}$ concentrations $<0.2 \mathrm{ppb}$ have been excluded from this analysis.

to further reaction with $\mathrm{OH}$ ). These limitations of the OFR technique need to be corrected in order to relate OFR measurements to real atmospheric processes. $\mathrm{H}_{2} \mathrm{SO}_{4}$ formation is an analogous yet much simpler system compared to LVOC formation, so it can be used to validate the LVOC fate model. If the $\mathrm{H}_{2} \mathrm{SO}_{4}$ condenses onto aerosols, it will be measured as $\mathrm{SO}_{4}$ aerosol by the AMS. $\mathrm{SO}_{4}$ aerosol formation in the OFR was predicted by using estimated $\mathrm{OH}_{\text {exp }}$ to calculate how much ambient $\mathrm{SO}_{2}$ would be oxidized into $\mathrm{H}_{2} \mathrm{SO}_{4}$. The LVOC fate model was then used to determine $F_{\text {aer }}, F_{\text {wall }}$, and $F_{\text {exit }}$ for $\mathrm{H}_{2} \mathrm{SO}_{4}$, while $F_{\mathrm{OH}}$ was set equal to 0 since gas-phase $\mathrm{H}_{2} \mathrm{SO}_{4}$ will not continue to react with $\mathrm{OH}$ to produce volatile fragments. We used $D=1 \times 10^{-5} \mathrm{~m}^{2} \mathrm{~s}^{-1}$ for an $\mathrm{H}_{2} \mathrm{SO}_{4}$ molecule hydrated by $\mathrm{H}_{2} \mathrm{O}$ molecules in the gas phase at the relevant ambient pressure and humidity (Hanson and Eisele, 2000) and the best-fit value of $\alpha=0.65$ from Pöschl et al. (1998). An additional minor correction was applied to account for the fact that the $\mathrm{SO}_{2}+\mathrm{OH}$ reaction is relatively slow, so the effective $\tau_{\mathrm{OFR}}$ for $\mathrm{H}_{2} \mathrm{SO}_{4}$ molecules in the reactor can be less than the full OFR residence time depending on $\mathrm{OH}_{\text {exp }}$. Using the model results, the fraction of $\mathrm{H}_{2} \mathrm{SO}_{4}$ that does not condense onto aerosol was corrected for by dividing the newly produced $\mathrm{SO}_{4}$ mass measured with the AMS by $F_{\text {aer }}$.

The measured vs. predicted $\mathrm{SO}_{4}$ enhancement after $\mathrm{OH}$ oxidation in the OFR using the OFR185 method is shown in Fig. 6. The AMS measured $61 \%$ of the predicted $\mathrm{SO}_{4}$ en- hancement. After applying the correction for $\mathrm{H}_{2} \mathrm{SO}_{4}$ wall and sampling line losses as described in the previous paragraph, the measured and predicted $\mathrm{SO}_{4}$ enhancements agreed well, with a slope of 0.81 , and $R^{2}$ slightly increased from 0.80 to 0.85 . To illustrate the sensitivities of this model to key uncertain parameters, the effects of using the range of $\alpha=0.43-1$ given in Pöschl et al. (1998) and using the size distributions before or after oxidation in the OFR (as lower and upper bounds of CS) are shown in Fig. S10. Generally, the amount of $\mathrm{SO}_{4}$ formed after applying the $\mathrm{H}_{2} \mathrm{SO}_{4}$ wall and sampling line loss correction was consistent with the expected amount within the uncertainties. The amount of scatter introduced by applying the correction was larger when the amount of $\mathrm{SO}_{4}$ produced (and predicted) was close to 0 , when the $F_{\text {aer }}$ correction factor was less than $\sim 0.3$. This suggests that the LVOC fate model becomes more uncertain when the correction factors are large and $F_{\text {aer }}$ is close to 0 . However, this analysis demonstrates that a correction can be successfully applied for $\mathrm{H}_{2} \mathrm{SO}_{4}$ condensation, and that a similar correction should also be applied for LVOC condensation to accurately interpret the results of SOA formation in an OFR.

In the subsequent analyses, SOA formation is presented both applying and without applying a correction to account for incomplete LVOC condensation to aerosol in the reactor. The correction, hereafter referred to as the "LVOC fate correction", is applied by dividing the amount of SOA mass formed by $F_{\text {aer. }}$. The correction is only applied for data with eq. age $<5$ days. At higher exposures, it becomes unfeasible to apply the correction, because dividing small SOA mass formation by small fractions of condensation on aerosol results in large uncertainties. Instead, only uncorrected data are shown for eq. age $>5$ days, and they are interpreted as being dominated by heterogeneous oxidation.

\subsection{SOA mass enhancement vs. $\mathrm{OH}_{\mathrm{exp}}$}

Both the concentrations and relative fractions of ambient SOA precursor gases changed between day and night. They were dominated by $\mathrm{MBO}+$ isoprene (under ambient $\mathrm{OH}$ chemistry) during the day and by MT+SQT (under ambient $\mathrm{O}_{3} / \mathrm{NO}_{3}$ chemistry) at night (Fry et al., 2013). SOA will be formed in the OFR from these changing VOC mixtures and any other gases present in the ambient air that enters the reactor, so it might be expected that different amounts of SOA production would be observed during daytime vs. nighttime. Figure 7 shows daytime and nighttime OA enhancement as a

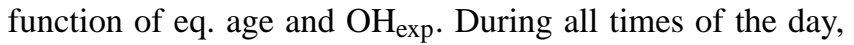
$\mathrm{OA}$ enhancement was largest in the range of 0.4-1.5 eq. days of photochemical aging, hereafter referred to as the age range of maximum OA enhancement. The diurnal profile of the OA enhancement in this range (inset of Fig. 7) shows that the maximum OA enhancement follows a pattern that is more nuanced than strictly daytime vs. nighttime, with a peak of SOA production in the early morning. Net loss of OA was observed above 10 eq. days of aging, consistent with the LVOC 
fate model and the interpretation that heterogeneous oxidation dominates at high eq. ages. This is also consistent with previous studies of heterogeneous $\mathrm{OH}$ oxidation of $\mathrm{OA}$ in a flow tube (George et al., 2008) and with results with the OFR in the Los Angeles urban area (Ortega et al., 2015).

As shown in Fig. 7, OA enhancement shows a strong difference between daytime and nighttime. However, SOA formation potential in the OFR should not be a function of time of day itself. Rather, this is thought to be a coincidental dependence based on the SOA precursor gas concentrations that change in a diurnal manner. In other words, this $\mathrm{OH}$ oxidation in the OFR is not meant to reproduce true ambient nighttime chemistry; rather it allows us to measure SOA formation from $\mathrm{OH}$ oxidation of the true mix of ambient gases as it evolves with time of day, including nighttime. In fact, the lack of ambient nighttime $\mathrm{OH}$ oxidation may help explain the increased SOA formation potential when nighttime air is oxidized by $\mathrm{OH}$ in the OFR.

These measurements were made in a pine forest dominated by MT (Ortega et al., 2014). As an alternative to separating by time of day, the data are separated by ambient MT concentrations in Fig. 8. The magnitude of SOA formation increased with ambient MT concentrations, ranging from no formation up to greater than $6 \mu \mathrm{g} \mathrm{m}^{-3} \mathrm{OA}$ enhancement (up to $3 \mu \mathrm{g} \mathrm{m}^{-3}$ enhancement without the LVOC fate correction). For the range of ages with maximum OA enhancement (0.41.5 eq. days), a correlation is observed between OA enhancement and MT concentrations $\left(R^{2}=0.56\right)$. Of course, MT may not be the only important precursors driving this correlation. Other gases that are correlated with MT, e.g., SQT $\left(R^{2}=0.70\right.$ with MT, shown in Fig. S11) or MT reaction products, may also contribute to the observed correlations. Although MT emissions are strongest during daytime due to their positive temperature dependence, their concentrations are higher at night due to the shallower nighttime boundary layer and reduced oxidation rate (Kim et al., 2010).

We observed much less SOA formation during the daytime, when concentrations of $\mathrm{MBO}+$ isoprene peaked but MT concentrations were lower. We note that SOA formation mechanisms that involve heterogeneous uptake followed by multiphase reactions are not efficiently simulated by the OFR, as their timescales are not shortened proportionally to increased $\mathrm{OH}$ concentrations ( $\mathrm{Hu}$ et al., 2016). This includes the isoprene epoxydiol (IEPOX) pathway from isoprene (Paulot et al., 2009) and the similar pathway proposed for MBO (Zhang et al., 2012). While SOA formation from isoprene in an OFR has been demonstrated (Lambe et al., 2015), the total SOA formation potential from $\mathrm{MBO}+$ isoprene may be underestimated in our study.

OA enhancement from the OFR185 and OFR254-70 modes of operation are compared in Fig. 7. Because these were performed with the same physical reactor, we could only perform one of them at a time (see Fig. S7). Since ambient MT concentrations changed over the course of the campaign and they correlated with the amount of SOA formed in the reactor, this effect needed to be corrected before the results of the two reactor modes could be compared. The positive OA enhancement for the OFR254-70 data was multiplied by the ratio of average MT concentrations between the OFR185 and OFR254-70 periods (a factor of 1.8). From Fig. 7, we conclude that there were no major differences in the amount of SOA formation between the OFR185 and OFR254-70 methods over the range of ages measured in this campaign. Minor differences in SOA formation between the two methods are likely a result of limits on the ability to determine the proper eq. age (especially for low ages in OFR254-70 as discussed in Sect. 2.3) or due to real changes in ambient SOA precursor gases, since the measurements using each method were not simultaneous. Additional comparisons of both methods sampling the same air, carefully designed and controlled to more accurately determine low ages in OFR254-70, would be useful to further explore this issue. Since the OFR185 mode is experimentally simpler and does not require addition of $\mathrm{O}_{3}$ (with associated issues of mixing, dilution, possible contamination, etc.), and since the OFR185 mode more faithfully simulates $\mathrm{OH}$ chemistry due to reduced $\mathrm{O}_{3}$ concentrations (Peng et al., 2015b), we recommend the OFR185 mode of operation for future OFR studies of $\mathrm{OH}$ oxidation in forested areas.

\subsection{Condensation vs. nucleation in the OFR}

When gas-phase molecules are oxidized and achieve a low enough volatility, they can condense onto existing particles (or other surfaces) or nucleate/grow new particles. The difference can be important experimentally because nucleation may produce some particles too small for the size range of the AMS, and it also increases surface area more efficiently than condensation to preexisting particles. Changes in the size distributions measured by the SMPS are used here to investigate the relative importance of these processes.

Particle volume size distributions of air oxidized over the full range of eq. photochemical ages in the flow reactor are shown in Fig. 9, during a period with relatively large OA enhancement in order to clearly demonstrate the behavior. $\mathrm{OH}$ oxidation in the reactor resulted in substantial new particle formation and growth, as well as growth of the preexisting ambient particles. The maximum enhancement in both particle modes occurred at an eq. age of $\sim 1$ day, consistent with AMS measurements of total mass enhancement. At higher ages, the new particle mode decreased in magnitude and diameter and eventually was not present at the highest ages. This is consistent with the results of the LVOC fate model, where at high eq. ages organic gases are rapidly oxidized into smaller volatile products that do not condense. The accumulation mode was also depleted at higher eq. ages, consistent with heterogeneous oxidation leading to fragmentation and evaporation of OA. The observed nucleation at lower eq. ages likely results from some combination of $\mathrm{H}_{2} \mathrm{SO}_{4}$ and ex- 


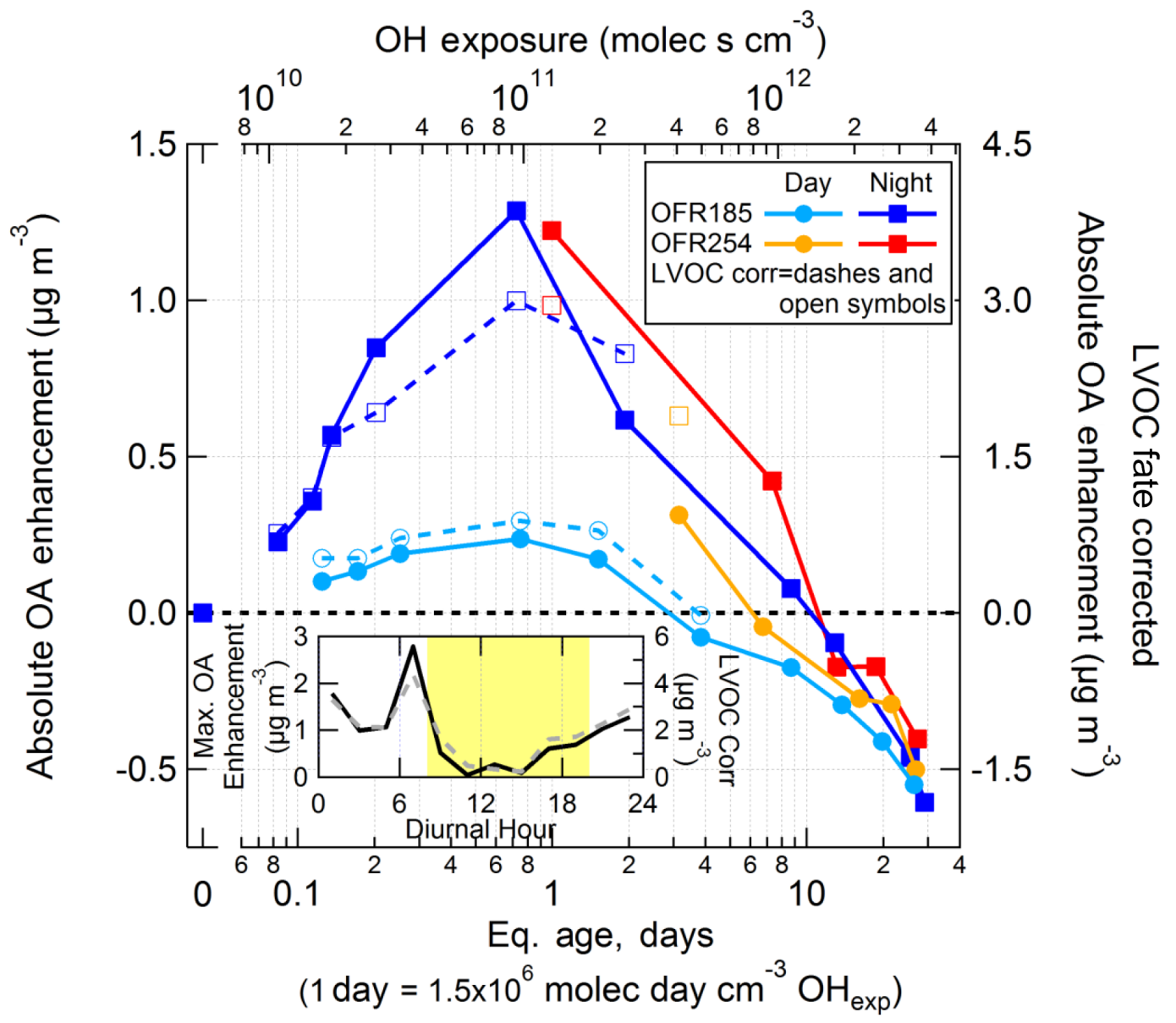

Figure 7. Comparison of absolute OA enhancement from OH oxidation using the OFR185 and OFR254-70 methods, binned by photochemical age and separated into daytime (08:00-20:00 LT) and nighttime (20:00-08:00 LT) to reflect the changes in ambient SOA precursors between day and night. Data are shown with (right axis, open symbols, and dashed lines) and without (left axis, closed symbols, and solid lines) the LVOC fate correction described in Sect. 3.3. Inset: the maximum OA enhancement (all data 0.4-1.5 days eq. age) as a function of time of day, with (dashed) and without (solid) the LVOC fate correction. OFR254-70 measurements with positive OA enhancement were multiplied by the ratio of ambient MT concentrations measured during OFR185 vs. OFR254-70 sampling periods (ratio = 1.8). Negative OA enhancements were not normalized in this way since the amount of mass lost due to heterogeneous oxidation would not necessarily correlate with ambient MT concentrations.

tremely low volatility organic compounds (ELVOCs; Kirkby et al., 2011; Ehn et al., 2014).

For the data shown in Fig. 9, a larger fraction of SOA molecules condensed onto the freshly nucleated particle mode than onto the preexisting particles. This behavior likely depends on the availability and position of the CS in the size distribution. With the small aerosol concentrations during this campaign, the CS from the new small particles sometimes competed with the CS from ambient particles. During periods when the CS entering the OFR in ambient air was larger, it reduced the condensation of SOA onto new particles, consistent with the lower importance of this mode for an OFR study in the Los Angeles area (Ortega et al., 2015). These results support the possibility of using flow reactors to study the potential for new particle formation and growth in different ambient air masses and sources (Ezell et al., 2014; Chen et al., 2015).

\subsection{Sources of SOA in ambient air}

\subsubsection{SOA mass formed vs. mass predicted from VOCs}

Many previous studies have measured the yields of SOA from oxidation of VOCs in chambers. Those experiments were generally performed under controlled conditions, with detailed information about the type and amount of VOCs available to form SOA at the beginning of the experiment. In this study, we also measured the yield of SOA from oxidation of organic gases, but in this case we started with a complex mixture of ambient organic gases, with some species not being directly measured or speciated. Therefore, the method 


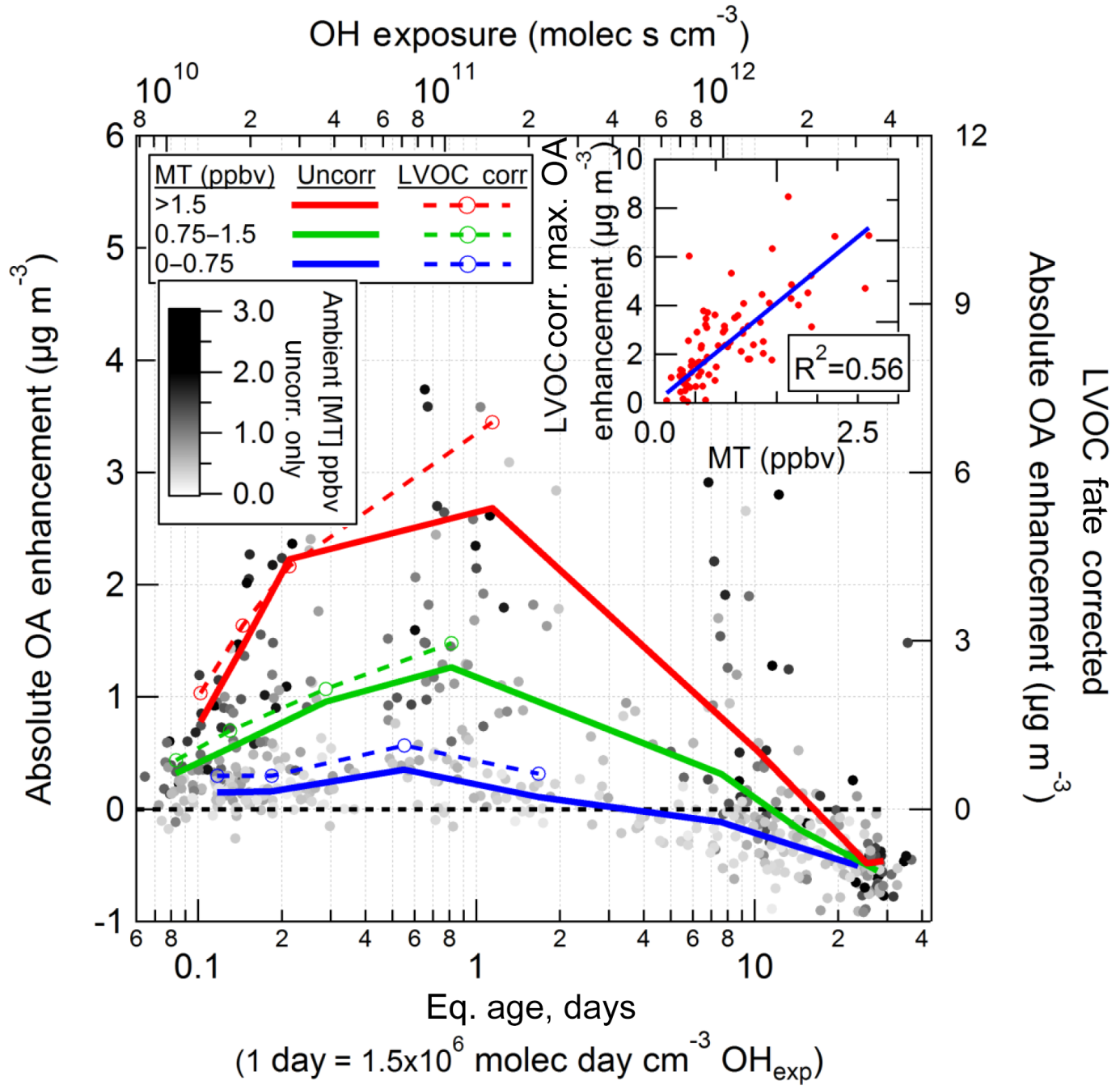

Figure 8. OA enhancement from OH oxidation of ambient air using the OFR185 method as a function of photochemical age. All data points (uncorrected only) are shown, shaded by in-canopy MT concentrations. Average OA enhancements of age quantiles with equal number of data points with (right axis, dashed lines) and without (left axis, solid lines) the LVOC fate correction are also shown, separated into low (0 to $0.75 \mathrm{ppbv})$, medium ( 0.75 to $1.5 \mathrm{ppbv})$, and high (> $1.5 \mathrm{ppbv})$ ambient MT concentration ranges. The inset shows the correlation $\left(R^{2}=0.56\right)$ between the LVOC fate corrected maximum OA enhancement (0.4-1.5 eq. days of aging) and in-canopy MT concentrations.

used here provided a measure of the total SOA formation (or destruction) as a function of oxidant exposure from all ambient gases present, measured and unmeasured. The total SOA formation in the OFR was compared to the amount predicted from measured VOCs. SOA formation was predicted by applying low- $\mathrm{NO}_{x}$, OA-concentration-dependent, chamber-derived aerosol yields to the ambient VOC concentrations predicted to react in the OFR based on $\mathrm{OH}_{\text {exp }}$. Estimated fractions reacted were $>99 \%$ of ambient MT, SQT, and isoprene, and $\sim 45 \%$ of toluene $+p$-cymene in the age range of $0.4-1.5$ eq. days. The yields used to predict SOA formation were calculated for each individual data point as a function of the OA mass concentration measured after oxidation in the OFR, using the two- or four-product basis set parameterizations listed in Table 3 (Henze and Seinfeld, 2006;
Tsimpidi et al., 2010). With an average post-oxidation OA concentration of $4.1 \mathrm{~g} \mathrm{~m}^{-3}$ with the LVOC fate correction applied, this resulted in campaign-average SOA yields of 12.5 , $13.2,13.8$, and $3.2 \%$ for MT, SQT, toluene, and isoprene, respectively. Previous experiments have shown SOA yields from various precursor gases oxidized in the OFR to be on the same order as yields from large environmental chambers (Kang et al., 2007, 2011; Lambe et al., 2011b, 2015). These yield values reflect the amount of SOA that forms after several generations of gas-phase oxidation of precursor gases. We do not include additional "aging" of the precursors through additional oxidation steps, as such parameterizations are not well supported experimentally.

The comparison of maximum measured vs. predicted SOA formation in Fig. 10 shows that approximately 4.4 times 


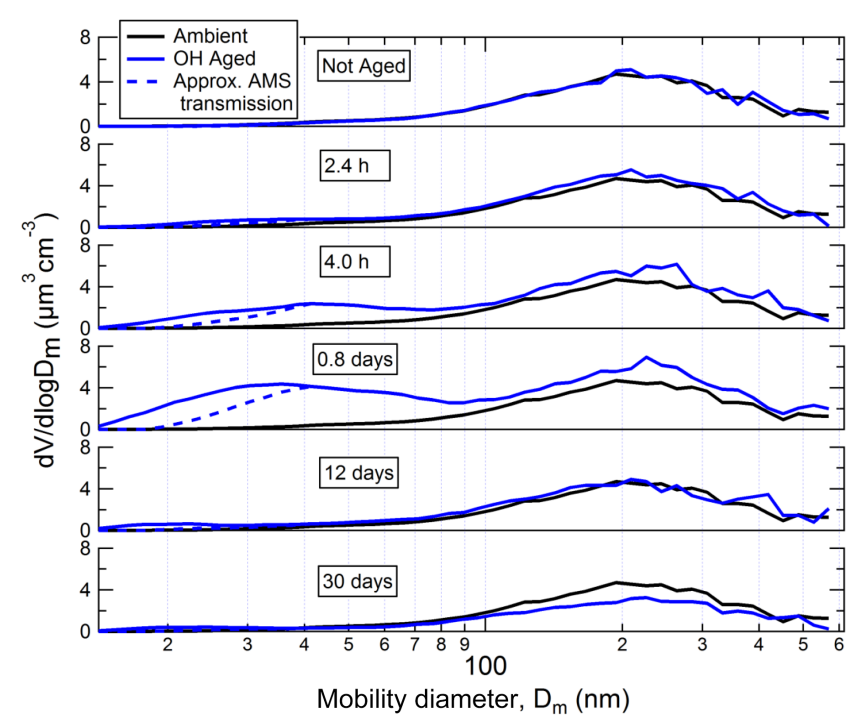

Figure 9. SMPS volume size distributions after $\mathrm{OH}$ oxidation using the OFR185 method, labeled by photochemical age and compared to concurrent ambient measurements. Each of the six $\mathrm{OH}$-aged size distributions is an average of six SMPS scans from the night of 28-29 July, when relatively large OA enhancement was observed and the ambient aerosol dry surface area was in the range of 80$100 \mu \mathrm{m}^{2} \mathrm{~cm}^{-3}$. Dashed lines represent the approximate size distributions that were transmitted through the AMS aerodynamic lens (for which a correction was applied to reported OA values as discussed in Sect. S3). Scans with large OA enhancement were used in order to more clearly illustrate the condensation vs. nucleation behavior in the OFR, so the AMS lens transmission correction in this figure appears larger than average. All scans have been corrected for small particle losses to sampling lines (Sect. S1).

more SOA was formed than predicted from MT, SQT, toluene $+p$-cymene, and isoprene. If the LVOC fate correction is not applied, still 3.1 times more SOA is measured than predicted (Fig. S12). Note that, while the LVOC fate correction led to approximately a factor-of- 2.5 increase in OA enhancement (seen in Figs. 7 and 8), it causes only a factor-of1.4 increase in the slope in Fig. 10. This is because the higher OA concentrations also lead to higher predicted SOA formation due to increased SOA yields (resulting from increased partitioning to the particle phase).

MT were the dominant SOA precursors, contributing an average of $87 \%$ to predicted SOA formation, with SQT, toluene $+p$-cymene, and isoprene contributing 5,3 , and $5 \%$, respectively. Other known VOCs that form SOA, such as benzene or xylenes, were present in such low concentrations that they would contribute even smaller percentages to predicted SOA formation, so they were not included in this analysis.

The correlation between measured and predicted SOA was $R^{2}=0.65$, indicating that SOA formation potential was controlled mainly by MT and other biogenic gases with similar concentration diurnal patterns, including SQT.
Table 3. Low-NO $\mathrm{NOA}_{x}$ yield parameters using basis sets, used to estimate SOA yields from VOCs in the OFR (Sect. 3.6.1).

\begin{tabular}{|c|c|c|c|c|}
\hline & \multicolumn{4}{|c|}{$\begin{array}{c}C^{*} \text { saturation vapor concentrations } \\
\left(\mu \mathrm{g} \mathrm{m}^{-3} \text { at } 298 \mathrm{~K}\right)\end{array}$} \\
\hline & 1 & 10 & 100 & 1000 \\
\hline $\mathrm{MT}^{\mathrm{a}}$ & 0.107 & 0.092 & 0.359 & 0.600 \\
\hline $\mathrm{SQT}^{\mathrm{a}}$ & 0.075 & 0.150 & 0.750 & 0.900 \\
\hline \multirow[t]{3}{*}{ Toluene $^{\mathrm{a}}$} & 0.075 & 0.225 & 0.375 & 0.525 \\
\hline & \multicolumn{4}{|c|}{$\begin{array}{c}C^{*} \text { saturation vapor concentrations } \\
\left(\mu \mathrm{g} \mathrm{m}^{-3} \text { at } 295 \mathrm{~K}\right)\end{array}$} \\
\hline & \multicolumn{2}{|c|}{0.6} & \multicolumn{2}{|c|}{116} \\
\hline Isoprene $^{b}$ & \multicolumn{2}{|c|}{0.0288} & \multicolumn{2}{|c|}{0.232} \\
\hline
\end{tabular}

Toluene also likely originated at least partially from biogenic sources at this site (Misztal et al., 2015). A diurnal plot of the measured maximum (0.4-1.5 days eq. age) and predicted SOA formation is shown in Fig. 11, along with ambient MT, SQT, toluene $+p$-cymene, and MBO+isoprene concentrations (and S/IVOC concentrations, discussed in Sect. 3.6.2). SOA formation followed a similar diurnal pattern to MT, SQT, and toluene+ $+p$-cymene, including a substantial increase just after sunrise at 07:00 LT. SOA formation in the OFR followed a very different diurnal pattern than ambient $\mathrm{MBO}+$ isoprene, supporting the conclusion that $\mathrm{MBO}+$ isoprene was an insignificant contributor to SOA formation in the OFR for the ambient conditions of this campaign.

In order for SOA formation in the OFR to be fully explained by the ambient VOCs, the SOA yields would have needed to be approximately a factor of 4.4 larger than the values used in this analysis. This would mean, e.g., a $55 \%$ yield from MT with the OA concentrations of only $4.1 \mu \mathrm{g} \mathrm{m}^{-3}$ (34\% at $2.9 \mu \mathrm{g} \mathrm{m}^{-3}$ if the LVOC fate correction is not applied), which is inconsistent with previous OFR and chamber studies that have only achieved such high SOA yields in experiments with over an order of magnitude higher OA concentrations (Kang et al., 2007, 2011; Tsimpidi et al., 2010; Lambe et al., 2011b, 2015). Accounting for S/IVOC wall losses in such experiments (Matsunaga and Ziemann, 2010; Zhang et al., 2014) or including aging parameterizations (Tsimpidi et al., 2010) might lessen this discrepancy, but is unlikely to be the entire answer. Therefore, this analysis strongly suggests that there are other gases in ambient air than the VOCs measured by the PTR-TOF-MS that make important contributions to SOA formation. 


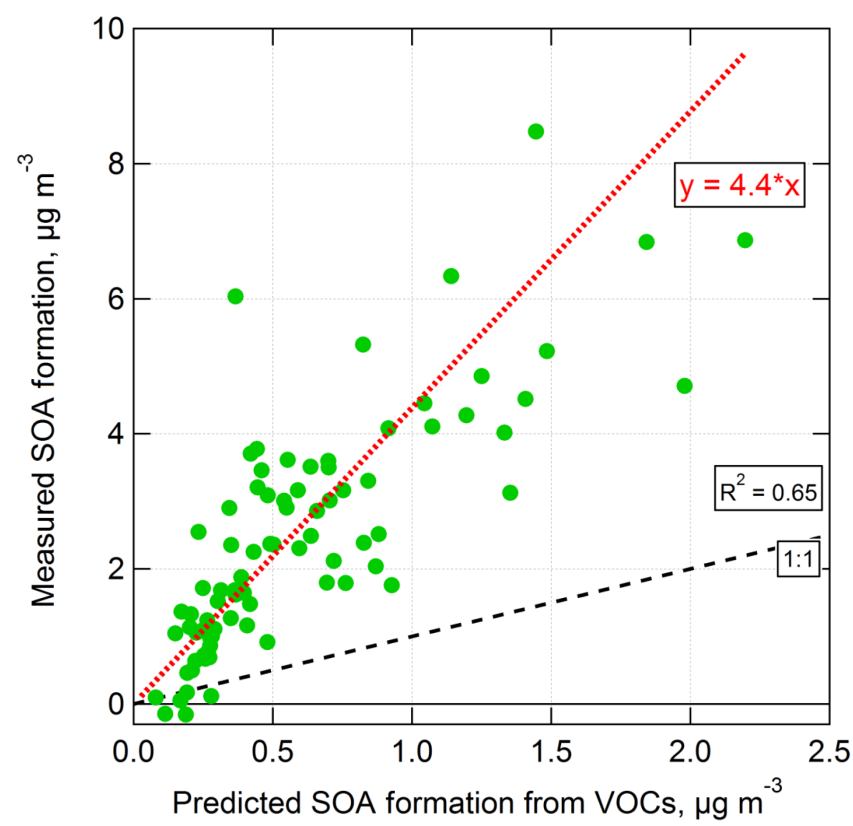

Figure 10. Measured vs. predicted SOA formation from $\mathrm{OH}$ oxidation of ambient air in an OFR using the OFR185 method. Only the range of photochemical ages with the highest SOA formation (0.4-1.5 eq. days) was used, and the LVOC fate correction was applied. Predicted SOA formation was calculated by applying OA concentration-dependent yields (average of 12.5, 13.2, 13.8, and $3.2 \%$ for MT, SQT, toluene+ $+p$-cymene, and isoprene, respectively, with average OA concentration of $4.1 \mu^{-3} \mathrm{~m}^{-3}$ ) to VOCs reacted in the OFR (Henze and Seinfeld, 2006; Tsimpidi et al., 2010). The amount of reacted VOCs was estimated using $\mathrm{OH}_{\exp }$ and ambient VOC concentrations. If a nonzero $y$ intercept is allowed, the regression line becomes $y=5.0 x-0.5$.

\subsubsection{SOA mass formed vs. predicted from S/IVOCs}

While the lowest-volatility organic matter (i.e., OA) is measured by the AMS and the highest-volatility range (VOCs and some IVOCs) is sampled by the PTR-TOF-MS, there is a substantial range of S/IVOCs between them. The gases that enter the OFR as S/IVOCs are the most likely source of SOA formation contributing to the factor-of-4.4 discrepancy in Sect. 3.6.1. During the BEACHON-RoMBAS campaign, measurements were made using the TD-EIMS instrument to quantify the bulk (volatility-resolved) ambient S/IVOC mass (Hunter et al., 2016). Other techniques at the site identified and quantified various subsets of the S/IVOCs (Yatavelli et al., 2014; Chan et al., 2016). All of the measurements are compiled in Hunter et al. (2016) to determine the total average organic volatility distribution during the campaign, which shows that S/IVOCs were the only pool of gas-phase species that could possibly produce as much SOA mass as observed in our study.

The average bulk S/IVOC mass concentrations measured with the TD-EIMS are shown as a function of $\log \left(C^{*}\right)$ in

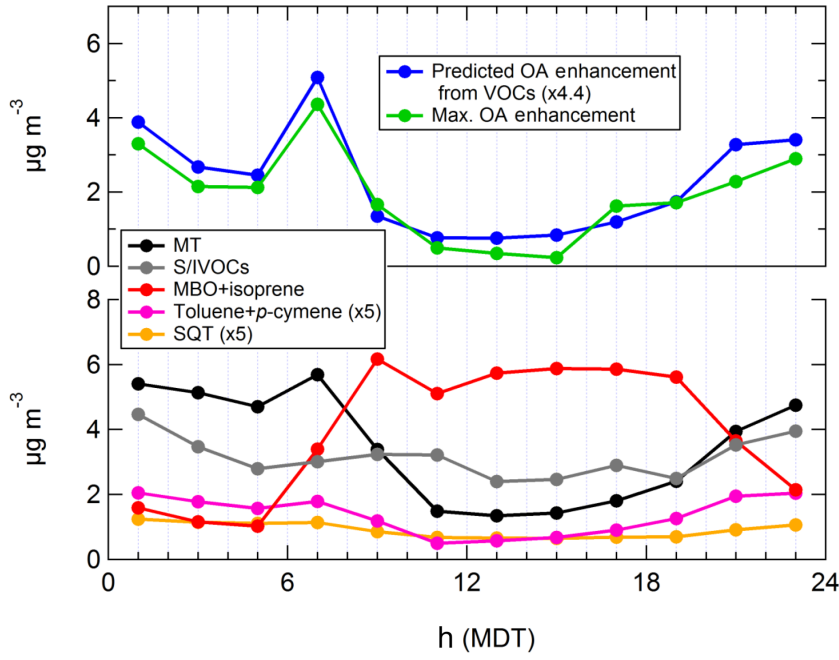

Figure 11. Top: diurnal maximum measured OA enhancement (all data from 0.4 to 1.5 eq. days of aging, LVOC fate corrected) in the OFR from $\mathrm{OH}$ oxidation using the OFR185 method, and predicted OA formation from measured VOCs $(\times 4.4)$. Bottom: ambient MT, SQT $(\times 5)$, toluene $+p$-cymene $(\times 5), \mathrm{MBO}+$ isoprene, and S/IVOC mass concentrations vs. time of day.

the inset of Fig. 12. In Hunter et al. (2016), this mass was interpreted as being an approximate lower limit to S/IVOC mass, assuming that the S/IVOCs measured by Yatavelli et al. (2014), by Chan et al. (2016), and by the PTR-TOF-MS were subsets of the TD-EIMS measurement. The upper limit is to assume that each instrument measured a different set of S/IVOCs with no overlap and would be $\sim 3.2$ times larger than the mass shown in the inset of Fig. 12. With the substantial temporal overlap between OFR185 operation and TDEIMS measurements, it is feasible to perform a point-bypoint analysis using the full TD-EIMS time series (shown in Fig. S7) to determine what the SOA yield of the lower-limit S/IVOC mass would need to be in order to fully explain the amount of SOA formed from $\mathrm{OH}$ oxidation in the OFR.

Ideally, the total mass of S/IVOCs at each data point that would be converted into SOA by oxidation would be determined by multiplying the mass in each volatility bin by the SOA yields of each bin. Since experimental measurements of the aerosol yields of such gases are generally not available and the ambient mixture of S/IVOCs was not fully speciated, we instead proceed under the assumption that all of the SOA formation that was not due to the previously discussed PTRTOF-MS-measured VOCs came instead from the mass measured in the $C^{*}=10^{1}-10^{7} \mu \mathrm{g} \mathrm{m}^{-3}$ volatility bins, with one correction. Since SQT are typically in the $C^{*}=10^{5} \mu \mathrm{g} \mathrm{m}^{-3}$ range, we subtracted the SQT mass measured by the PTRTOF-MS from the bulk S/IVOC mass (a subtraction of $6 \%$ of the total TD-EIMS measurement), to avoid double counting due to this expected measurement overlap. While MT are in the $C^{*}=10^{7} \mathrm{\mu g} \mathrm{m}^{-3}$ volatility bin, that bin is at the up- 


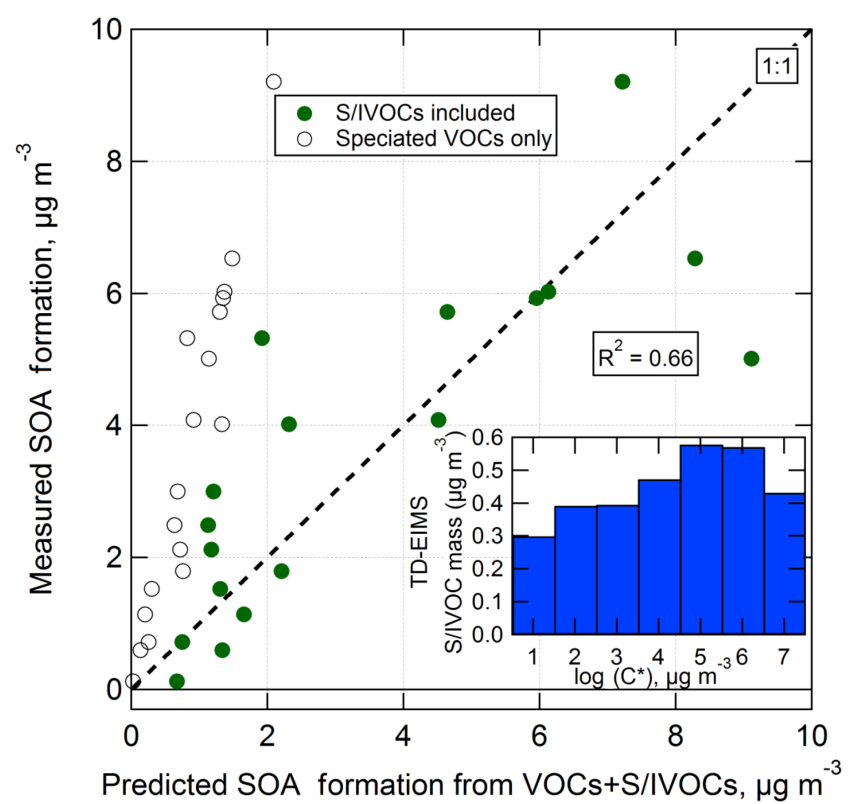

Figure 12. Measured vs. predicted SOA formation from $\mathrm{OH}$ oxidation of ambient air in an OFR using the OFR185 method. Only the range of photochemical ages with the highest SOA formation (0.41.5 eq. days) was used, and the LVOC fate correction was applied. Predicted SOA formation is estimated using VOCs (described in Sect. 3.6.1) including and without including an empirical $58 \%$ SOA yield from S/IVOCs measured by the TD-EIMS (a lower limit of total S/IVOCs). Inset: average S/IVOC concentrations as a function of the $\log$ of the saturation vapor concentration $C^{*}$. This comparison includes all data for which S/IVOCs and SOA formation in the OFR were concurrently measured (26, 28-29 July; 9-10, 12-13 August). For some data points, PTR-TOF-MS data were not available, so the VOC contribution was estimated using the linear fit in Fig. 10.

per volatility limit of the TD-EIMS measurement capability. Some gases in that bin were sampled, but MT were expected to be too volatile to be measured (Hunter et al., 2016). This was supported by the fact that the campaign-average mass in the $C^{*}=10^{7} \mu \mathrm{g} \mathrm{m}^{-3}$ bin was only $0.43 \mu \mathrm{g} \mathrm{m}^{-3}$, which would correspond to only approximately $0.1 \mathrm{ppbv}$ MT, if there were no other gases in that bin. The campaign-average in-canopy MT concentration measured by the PTR-TOF-MS was approximately $0.8 \mathrm{ppbv}$.

For the lower-limit S/IVOC mass case, the average SOA yield of the total S/IVOCs was determined by finding the yield value that made the slope of SOA measured vs. predicted from VOCs+S/IVOCs equal to 1 . As shown in Fig. 12, an average SOA yield of $58 \%$ for the bulk S/IVOC mass was required in order to bring the measured vs. predicted SOA formation into optimal agreement in this time series analysis. The correlation between measured and predicted SOA formation was $R^{2}=0.66$. Attempts were made to optimize the correlation between measured and predicted SOA formation by applying arbitrary $C^{*}$-dependent yields, but this did not result in significantly better correlations. Since speciated
S/IVOC measurements as well as yields for each volatility bin (which may have varied with diurnal changes in the composition of each bin) were not available, we concluded that further detailed interpretation of SOA production from the measured S/IVOCs would be under-constrained

As mentioned above, this average SOA yield for S/IVOCs of $58 \%$ was estimated by assuming the lower-limit case where the total ambient S/IVOC mass was sampled by the TD-EIMS. The upper-limit mass case in Hunter et al. (2016) assumed that the several instruments that measured S/IVOCs were measuring different subsets of total S/IVOCs, so the measurements needed to be summed in order to determine the total mass concentration. Due to limited temporal overlap between all instruments, the analysis in Hunter et al. (2016) was performed on campaign-average measurements. For this reason, the average SOA yield of S/IVOCs for the upper-limit case is also done using the campaign-average values instead of the time series analysis that was possible for the lowerlimit case. The average upper- and lower-limit S/IVOC mass concentrations were 10 and $3.1 \mu \mathrm{g} \mathrm{m}^{-3}$. To estimate the SOA yield of S/IVOCs in the upper-limit case, the TD-EIMS time series data were multiplied by 3.2 , so that they reflected a campaign average of $10 \mu \mathrm{g} \mathrm{m}^{-3}$. Using this upper-limit mass time series, an average SOA yield for S/IVOCs of $18 \%$ was needed to bring measured vs. predicted SOA formation in the OFR into agreement. This makes the assumption that the ratio of S/IVOC mass measured by each technique was always constant.

While measurements of SOA yields for speciated S/IVOCs are limited, especially for the relatively low OA concentrations in this study, previous work suggests that this range of $18-58 \%$ yield is reasonable. A yield of $51 \%$ was measured for $n$-heptadecane $\left(C^{*}=10^{4} \mu \mathrm{g} \mathrm{m}^{-3}\right)$ with $\mathrm{OA}=15.4 \mu \mathrm{g} \mathrm{m}^{-3}$ under high-NO${ }_{x}$ conditions (Presto et al., 2010). Yields can be even higher from cyclic compounds (Lim and Ziemann, 2009; Tkacik et al., 2012) and under low$\mathrm{NO}_{x}$ conditions (Ng et al., 2007; Lane et al., 2008). SOA yields from several other IVOCs (naphthalene and alkylnapthalenes) under low- $\mathrm{NO}_{x}$ conditions were determined to be $58-73 \%$ with OA concentrations of $10-40 \mu \mathrm{g} \mathrm{m}^{-3}$ (Chan et al., 2009).

This analysis suggests that $\mathrm{OH}$ oxidation of organic gases in a parcel of ambient pine forest air can potentially produce approximately 3.4 times more SOA from S/IVOC gases than from VOCs. This does not provide information about the sources of the lower-volatility organic gases in this parcel. They may be directly emitted, formed as oxidation products of VOCs that were emitted upwind of this parcel, or some combination of these two options. Ambient MT and S/IVOC concentrations measured by the TD-EIMS exhibit a modest correlation $\left(R^{2}=0.43\right.$, shown in Fig. S13), suggesting that the S/IVOCs may at least partially come from a biogenic source related to the emission of MT. For example, $\mathrm{O}_{3}$ and $\mathrm{NO}_{3}$ may react with the $\mathrm{C}=\mathrm{C}$-containing $\mathrm{MT}$ and SQT emissions during nighttime, leading to a buildup of 
oxidation product $\mathrm{S} / \mathrm{IVOCs}$ that lack $\mathrm{C}=\mathrm{C}$ double bonds and would generally not react further with $\mathrm{O}_{3}$ and $\mathrm{NO}_{3}$ (Atkinson, 1997). If this occurs, then OFR oxidation is merely starting with precursors that are partway through the aging process from VOC emission to SOA formation. Variations in the ratio of measured to predicted SOA formation in Figs. 10 and 12 could be due partly to variations in the ratio of the concentrations of S/IVOCs to VOCs due to changes in the meteorological or chemical conditions of the atmosphere, or from periodic changes in the biogenic and/or anthropogenic sources of S/IVOCs. However, as shown in Fig. 11, the diurnal profile of S/IVOC concentrations showed a relatively smaller increase in concentrations at night compared to MT or measured SOA formation. Since emissions generally change with time of day, it would not be unreasonable to expect the speciation and SOA formation potential of ambient S/IVOCs to also change with time of day. Until the S/IVOCs in a data set such as this can be better speciated and quantified, these conclusions remain speculative.

\subsubsection{Sensitivity to LVOC fate model parameters}

The LVOC fate correction in this analysis led to a relatively large factor-of-2.5 increase in OA enhancement and factorof-1.4 increase in measured vs. predicted SOA formation. As the values of several of the model parameters are not well constrained, in this section we investigate the sensitivity of the LVOC fate correction to these parameters. Figure 13 shows the sensitivity of the slope of measured vs. predicted SOA formation from VOCs, as well as how that affected the range of SOA yields needed from S/IVOCs in order to explain the total SOA formation in the OFR. Sensitivity was tested for the following parameters: $k_{\mathrm{OH}}$; the number of reactions with $\mathrm{OH}$ before LVOCs are lost to volatile, non-condensable products; the SMPS size distribution used to calculate CS; $\alpha$; $k_{\mathrm{e}}$; and $D$.

The least-well-defined parameters in the model were likely $k_{\mathrm{OH}}$ and the number of reactions with $\mathrm{OH}$, especially since the analysis of $\mathrm{H}_{2} \mathrm{SO}_{4}$ condensation in Sect. 3.3.2 did not use them. However, the LVOC fate correction was relatively insensitive to these parameters, specifically for values of $k_{\mathrm{OH}}$ less than $3 \times 10^{-11} \mathrm{~cm}^{3} \mathrm{molec}^{-1} \mathrm{~s}^{-1}$ or when assuming $2+$ reactions with $\mathrm{OH}$. If we assume LVOCs always remain available to condense and never fragment, the slope reaches a lower asymptote of 4.1 . The model also showed a relatively low sensitivity to $k_{\mathrm{e}}$ and $D$ over several orders of magnitude.

The slope of measured vs. predicted SOA formation was more sensitive to the choice of CS and $\alpha$. The slope is mainly sensitive to CS when approaching the ambient (smaller) value. Since using the average value of CS worked well for the $\mathrm{H}_{2} \mathrm{SO}_{4}$ analysis (and the ambient CS gave poor results there), it is likely that the average CS is at least close enough to the proper value as not to cause systematic biases. Using values of $\alpha$ less than 1 led to a rapid increase in the magnitude of the LVOC fate correction. Values less than approximately

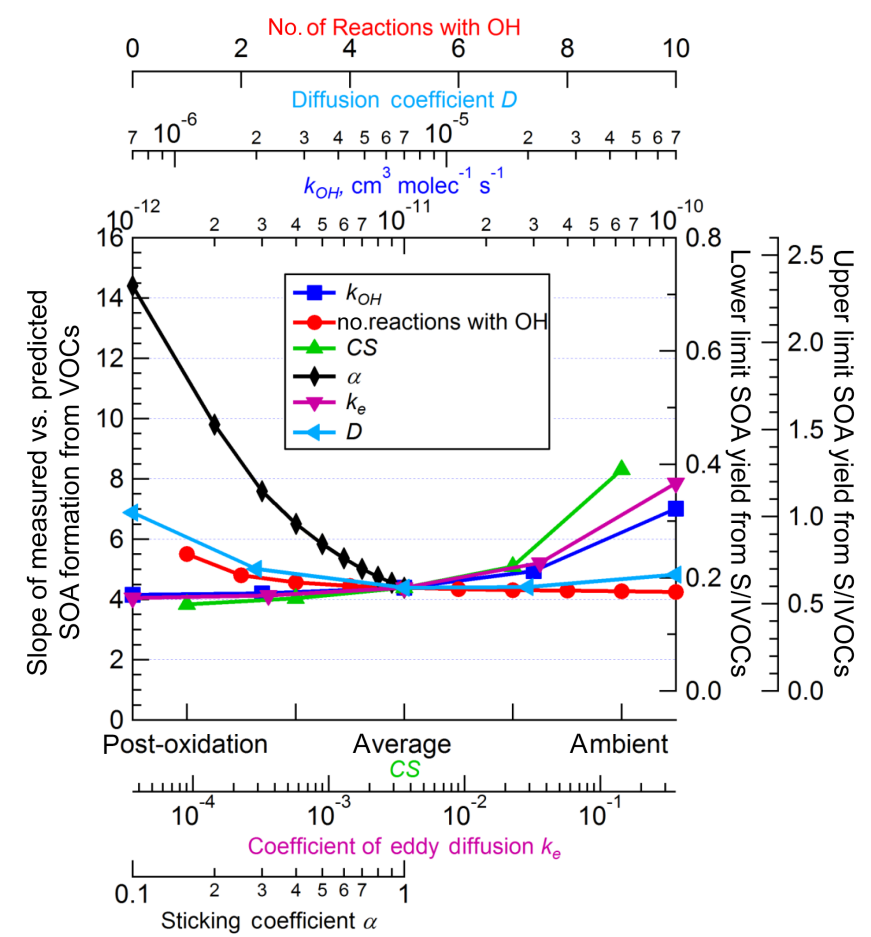

Figure 13. Sensitivity of the slope of measured vs. predicted SOA formation from VOCs, and of the range of SOA yields estimated for bulk S/IVOCs (same curves, different $y$ axes), to parameters in the LVOC fate model. The change in slope and yields is calculated by changing only one parameter at a time while keeping the rest at the following base case values: five reactions with $\mathrm{OH}, k_{\mathrm{OH}}=$ $1 \times 10^{-11} \mathrm{~cm}^{3}$ molec $^{-1} \mathrm{~s}^{-1}$, average of CS measured in ambient air and after OFR oxidation, $\alpha=1, k_{\mathrm{e}}=0.0036 \mathrm{~s}^{-1}$, and $D=7 \times$ $10^{-6} \mathrm{~m}^{2} \mathrm{~s}^{-1}$.

$\alpha=0.1$ would require the SOA yield from S/IVOCs to approach $100 \%$ as a lower limit, which is unlikely to be the case. In other words, if the sticking coefficient were very low (e.g., $\alpha<0.1$ ), it would be impossible to explain the amount of SOA formed from the carbon present in the gas phase. This suggests that $\alpha=1$ or close to 1 is a good approximation for the conditions in the OFR in this campaign and allows us to rule out values much lower than 1 .

It is noteworthy that none of the changes to these four parameters led to a substantial decrease in the slope of measured vs. predicted SOA formation. The parameters that can lead to a considerable increase in $F_{\text {aer }}$ are the CS and residence time of the OFR (i.e., time allowed for condensation onto particles, which is controlled by flow rate). However, these values were among the best-constrained parameters, since we had direct measurements of both during the campaign. This suggests that, while the LVOC fate correction was relatively large, it was unlikely to be much smaller. 


\section{Conclusions}

During the BEACHON-RoMBAS campaign, ambient air was oxidized by $\mathrm{OH}$ in an OFR to study in situ SOA formation from the ambient mixture of SOA precursors as they exist in a forest environment. SOA formation was measured semicontinuously, and the changes in both gas and particle phases were documented as a function of photochemical age. The amount of SOA formation increased with age to a maximum at $0.4-1.5$ days of eq. photochemical aging, coinciding with depletion of known SOA precursors measured with the PTR-TOF-MS. SOA formation in the OFR correlated with MT concentrations, both of which were typically larger during nighttime. Net SOA loss was observed at $>10$ days eq. age, consistent with heterogeneous oxidation processes being important only for the longest-lived aerosol (e.g., freetropospheric aerosol). Similar amounts of SOA formation were observed from both the OFR185 and OFR254-70 methods for the overlapping range of eq. ages ( $\sim 1-30$ days). Comparison at shorter ages was not possible because the OFR254-70 method, especially as it was employed during this campaign, was not suitable for measuring $<1$ eq. day of $\mathrm{OH}$ aging. Condensation onto preexisting ambient particles and nucleation and growth of small particles were both observed.

A modeling analysis of the fate of LVOCs in the OFR was presented. The validity of this model was evaluated using the simpler process of $\mathrm{SO}_{2}$ gas conversion to $\mathrm{SO}_{4}$ aerosol. The fraction of LVOCs that condense onto aerosols versus the other fates of LVOCs - including condensing on the reactor walls, exiting the reactor to condense on sampling lines, or reacting with $\mathrm{OH}$ to produce volatile fragmentation products - depends strongly on the aerosol surface area available for condensation. Our measurements rule out sticking coefficients much lower than 1. For ambient experiments in rural areas with low CS, for laboratory experiments without seed aerosol, or when sampling with a relatively short residence time, a large correction may be required. Addition of an aerosol seed to sample air with low aerosol CS (such as this study) would reduce the uncertainties associated with the LVOC fate correction. In urban areas or in laboratory studies with large seed aerosol surface area, the correction can be much smaller $(<20 \%)$. In either case, the relative timescales of key processes in the OFR need to be carefully considered in order to properly interpret the results of measured SOA formation.

The amount of SOA that could be produced from $\mathrm{OH}$ oxidation of the major VOC species measured at this site (MT, $\mathrm{SQT}$, toluene $+p$-cymene, and isoprene) was insufficient to explain the measured SOA formation in the reactor by a factor of 4.4. To our knowledge, this is the first time this has been demonstrated by comparing simultaneous VOC measurements with in situ SOA formation, particularly in a biogenic environment. A discrepancy this large is unlikely to be completely explained by incorrect yields for the speci- ated VOCs or by experimental uncertainties. The correlation between measured and predicted SOA formation suggests that the unidentified SOA precursors were of biogenic origin with a similar diurnal pattern to MT, SQT, and toluene $+p$-cymene. Novel TD-EIMS measurements quantified the reservoir of S/IVOCs, which are not measured efficiently by a PTR-TOF-MS and represent the only pool of gas-phase carbon at the site that could possibly explain the observed SOA. An SOA yield of $18-58 \%$ for the total mass of S/IVOCs measured was required to account for all of the SOA formation from $\mathrm{OH}$ oxidation in the OFR. This research points to a need to improve our understanding and measurement capabilities of S/IVOCs.

We have demonstrated how an OFR can be used in combination with a variety of aerosol and gas instruments to provide information about the net SOA formation potential of forest air. The OFR technique allows investigating the quantity and variability of SOA precursor gases that are present in ambient air. These results could be used to inform the treatment of S/IVOCs, such as VOC oxidation products, in SOA models. Future OFR experiments could be designed with additional specialized instrumentation to determine the molecular identities of S/IVOCs and investigate their specific SOA yields.

\section{The Supplement related to this article is available online at doi:10.5194/acp-16-2943-2016-supplement.}

Acknowledgements. We thank US NSF grants AGS-1243354 and AGS-1360834, NOAA grants NA13OAR4310063 and NA10OAR4310106, U.S. DOE ASR Program (Office of Science, BER, DE-SC0011105), Austrian Science Fund (FWF) project number L518-N20, and the US EPA (STAR 83587701-0) for partial support for this research. Brett B. Palm acknowledges support from a CIRES Graduate Student Research Fellowship and a US EPA STAR Graduate Fellowship (FP-91761701-0). Lisa Kaser acknowledges support from a DOC-fFORTE Fellowship of the Austrian Academy of Science. This work has not been formally reviewed by the US EPA. The views expressed are solely those of the authors, and the US EPA does not endorse any products or commercial services mentioned in this work. Amber M. Ortega acknowledges a fellowship from the DOE SCGP Fellowship Program (ORAU, ORISE). We are grateful to Alex Guenther and Jim Smith of NCAR for co-organizing the BEACHON-RoMBAS field campaign, to Andrew Turnipseed for $\mathrm{SO}_{2}$ measurements, and to the USFS Manitou Experimental Forest Observatory for site support.

Edited by: R. Holzinger 


\section{References}

Alarcón, P., Bohn, B., Zetzsch, C., Rayez, M.-T., and Rayez, J.-C.: Reversible addition of the $\mathrm{OH}$ radical to $p$-cymene in the gas phase: multiple adduct formation. Part 2, Phys. Chem. Chem. Phys., 16, 17315-17326, doi:10.1039/c4cp02073a, 2014.

Atkinson, R.: Gas-Phase Tropospheric Chemistry of Volatile Organic Compounds: 1. Alkanes and Alkenes, J. Phys. Chem. Ref. Data, 26, 215-290, doi:10.1063/1.556012, 1997.

Atkinson, R. and Arey, J.: Gas-phase tropospheric chemistry of biogenic volatile organic compounds: a review, Atmos. Environ., 37, 197-219, doi:10.1016/S1352-2310(03)00391-1, 2003.

Bruns, E. A., El Haddad, I., Keller, A., Klein, F., Kumar, N. K., Pieber, S. M., Corbin, J. C., Slowik, J. G., Brune, W. H., Baltensperger, U., and Prévôt, A. S. H.: Inter-comparison of laboratory smog chamber and flow reactor systems on organic aerosol yield and composition, Atmos. Meas. Tech., 8, 23152332, doi:10.5194/amt-8-2315-2015, 2015.

Calvert, J. G., Atkinson, R., Becker, K. H., Kamens, R. M., Seinfeld, J. H., Wallington, T. H., and Yarwood, G.: The Mechanisms of Atmospheric Oxidation of the Aromatic Hydrocarbons, Oxford University Press, New York, USA, 2002.

Cappa, C. D. and Jimenez, J. L.: Quantitative estimates of the volatility of ambient organic aerosol, Atmos. Chem. Phys., 10, 5409-5424, doi:10.5194/acp-10-5409-2010, 2010.

Chan, A. W. H., Kautzman, K. E., Chhabra, P. S., Surratt, J. D., Chan, M. N., Crounse, J. D., Kürten, A., Wennberg, P. O., Flagan, R. C., and Seinfeld, J. H.: Secondary organic aerosol formation from photooxidation of naphthalene and alkylnaphthalenes: implications for oxidation of intermediate volatility organic compounds (IVOCs), Atmos. Chem. Phys., 9, 3049-3060, doi:10.5194/acp-9-3049-2009, 2009.

Chan, A. W. H., Kreisberg, N. M., Hohaus, T., Campuzano-Jost, P., Zhao, Y., Day, D. A., Kaser, L., Karl, T., Hansel, A., Teng, A. P., Ruehl, C. R., Sueper, D. T., Jayne, J. T., Worsnop, D. R., Jimenez, J. L., Hering, S. V., and Goldstein, A. H.: Speciated measurements of semivolatile and intermediate volatility organic compounds (S/IVOCs) in a pine forest during BEACHON-RoMBAS 2011, Atmos. Chem. Phys., 16, 1187-1205, doi:10.5194/acp-161187-2016, 2016.

Chen, H., Ezell, M. J., Arquero, K. D., Varner, M. E., Dawson, M. L., Gerber, R. B., and Finlayson-Pitts, B. J.: New particle formation and growth from methanesulfonic acid, trimethylamine and water, Phys. Chem. Chem. Phys., 17, 13699-13709, doi:10.1039/C5CP00838G, 2015.

Chen, Q., Farmer, D. K., Schneider, J., Zorn, S. R., Heald, C. L., Karl, T. G., Guenther, A., Allan, J. D., Robinson, N., Coe, H., Kimmel, J. R., Pauliquevis, T., Borrmann, S., Pöschl, U., Andreae, M. O., Artaxo, P., Jimenez, J. L., and Martin, S. T.: Mass spectral characterization of submicron biogenic organic particles in the Amazon Basin, Geophys. Res. Lett., 36, L20806, doi:10.1029/2009GL039880, 2009.

Cross, E. S., Hunter, J. F., Carrasquillo, A. J., Franklin, J. P., Herndon, S. C., Jayne, J. T., Worsnop, D. R., Miake-Lye, R. C., and Kroll, J. H.: Online measurements of the emissions of intermediate-volatility and semi-volatile organic compounds from aircraft, Atmos. Chem. Phys., 13, 7845-7858, doi:10.5194/acp-13-7845-2013, 2013.

DeCarlo, P. F., Kimmel, J. R., Trimborn, A., Northway, M. J., Jayne, J. T., Aiken, A. C., Gonin, M., Fuhrer, K., Horvath, T., Docherty,
K. S., Worsnop, D. R., and Jimenez, J. L.: Field-Deployable, High-Resolution, Time-of-Flight Aerosol Mass Spectrometer, Anal. Chem., 78, 8281-8289, doi:10.1021/ac061249n, 2006.

DeCarlo, P. F., Dunlea, E. J., Kimmel, J. R., Aiken, A. C., Sueper, D., Crounse, J., Wennberg, P. O., Emmons, L., Shinozuka, Y., Clarke, A., Zhou, J., Tomlinson, J., Collins, D. R., Knapp, D., Weinheimer, A. J., Montzka, D. D., Campos, T., and Jimenez, J. L.: Fast airborne aerosol size and chemistry measurements above Mexico City and Central Mexico during the MILAGRO campaign, Atmos. Chem. Phys., 8, 4027-4048, doi:10.5194/acp-84027-2008, 2008.

Donahue, N. M., Robinson, A. L., Stanier, C. O., and Pandis, S. N.: Coupled Partitioning, Dilution, and Chemical Aging of Semivolatile Organics, Environ. Sci. Technol., 40, 2635-2643, doi:10.1021/es052297c, 2006

Ehn, M., Thornton, J. A., Kleist, E., Sipilä, M., Junninen, H., Pullinen, I., Springer, M., Rubach, F., Tillmann, R., Lee, B., LopezHilfiker, F., Andres, S., Acir, I.-H., Rissanen, M., Jokinen, T., Schobesberger, S., Kangasluoma, J., Kontkanen, J., Nieminen, T., Kurtén, T., Nielsen, L. B., Jørgensen, S., Kjaergaard, H. G., Canagaratna, M., Maso, M. D., Berndt, T., Petäjä, T., Wahner, A., Kerminen, V.-M., Kulmala, M., Worsnop, D. R., Wildt, J., and Mentel, T. F.: A large source of low-volatility secondary organic aerosol, Nature, 506, 476-479, doi:10.1038/nature13032, 2014.

Ervens, B.: Modeling the Processing of Aerosol and Trace Gases in Clouds and Fogs, Chem. Rev., 115, 4157-4198, doi:10.1021/cr5005887, 2015.

Ervens, B., Turpin, B. J., and Weber, R. J.: Secondary organic aerosol formation in cloud droplets and aqueous particles (aqSOA): a review of laboratory, field and model studies, Atmos. Chem. Phys., 11, 11069-11102, doi:10.5194/acp-1111069-2011, 2011.

Ezell, M. J., Chen, H., Arquero, K. D., and FinlaysonPitts, B. J.: Aerosol fast flow reactor for laboratory studies of new particle formation, J. Aerosol Sci., 78, 30-40, doi:10.1016/j.jaerosci.2014.08.009, 2014.

Farmer, D. K. and Cohen, R. C.: Observations of $\mathrm{HNO}_{3}, \Sigma \mathrm{AN}$, $\Sigma \mathrm{PN}$ and $\mathrm{NO}_{2}$ fluxes: evidence for rapid $\mathrm{HO}_{x}$ chemistry within a pine forest canopy, Atmos. Chem. Phys., 8, 3899-3917, doi:10.5194/acp-8-3899-2008, 2008.

Fry, J. L., Draper, D. C., Zarzana, K. J., Campuzano-Jost, P., Day, D. A., Jimenez, J. L., Brown, S. S., Cohen, R. C., Kaser, L., Hansel, A., Cappellin, L., Karl, T., Hodzic Roux, A., Turnipseed, A., Cantrell, C., Lefer, B. L., and Grossberg, N.: Observations of gas- and aerosol-phase organic nitrates at BEACHON-RoMBAS 2011, Atmos. Chem. Phys., 13, 8585-8605, doi:10.5194/acp-138585-2013, 2013.

George, I. J., Slowik, J., and Abbatt, J. P. D.: Chemical aging of ambient organic aerosol from heterogeneous reaction with hydroxyl radicals, Geophys. Res. Lett., 35, L13811, doi:10.1029/2008GL033884, 2008.

Goldstein, A. H. and Galbally, I. E.: Known and Unexplored Organic Constituents in the Earth's Atmosphere, Environ. Sci. Technol., 41, 1514-1521, doi:10.1021/es072476p, 2007.

Grieshop, A. P., Logue, J. M., Donahue, N. M., and Robinson, A. L.: Laboratory investigation of photochemical oxidation of organic aerosol from wood fires 1: measurement and simulation of 
organic aerosol evolution, Atmos. Chem. Phys., 9, 1263-1277, doi:10.5194/acp-9-1263-2009, 2009.

Hanson, D. R. and Eisele, F.: Diffusion of $\mathrm{H}_{2} \mathrm{SO}_{4}$ in Humidified Nitrogen: Hydrated $\mathrm{H}_{2} \mathrm{SO}_{4}$, J. Phys. Chem. A, 104, 1715-1719, doi:10.1021/jp993622j, 2000.

Hayes, P. L., Carlton, A. G., Baker, K. R., Ahmadov, R., Washenfelder, R. A., Alvarez, S., Rappenglück, B., Gilman, J. B., Kuster, W. C., de Gouw, J. A., Zotter, P., Prévôt, A. S. H., Szidat, S., Kleindienst, T. E., Offenberg, J. H., Ma, P. K., and Jimenez, J. L.: Modeling the formation and aging of secondary organic aerosols in Los Angeles during CalNex 2010, Atmos. Chem. Phys., 15, 5773-5801, doi:10.5194/acp-15-5773-2015, 2015.

Henze, D. K. and Seinfeld, J. H.: Global secondary organic aerosol from isoprene oxidation, Geophys. Res. Lett., 33, L09812, doi:10.1029/2006GL025976, 2006.

Hodzic, A., Jimenez, J. L., Madronich, S., Aiken, A. C., Bessagnet, B., Curci, G., Fast, J., Lamarque, J.-F., Onasch, T. B., Roux, G., Schauer, J. J., Stone, E. A., and Ulbrich, I. M.: Modeling organic aerosols during MILAGRO: importance of biogenic secondary organic aerosols, Atmos. Chem. Phys., 9, 6949-6981, doi:10.5194/acp-9-6949-2009, 2009.

Hodzic, A., Jimenez, J. L., Madronich, S., Canagaratna, M. R., DeCarlo, P. F., Kleinman, L., and Fast, J.: Modeling organic aerosols in a megacity: potential contribution of semi-volatile and intermediate volatility primary organic compounds to secondary organic aerosol formation, Atmos. Chem. Phys., 10, 5491-5514, doi:10.5194/acp-10-5491-2010, 2010.

Hu, W. W., Palm, B. B., Day, D. A., Campuzano-Jost, P., Krechmer, J. E., Peng, Z., de Sá, S. S., Martin, S. T., Alexander, M. L., Baumann, K., Hacker, L., Kiendler-Scharr, A., Koss, A., de Gouw, J. A., Goldstein, A. H., Seco, R., Canonaco, F., Prévôt, A. S. H., Brune, W. H., and Jimenez, J. L.: Long Lifetime of Ambient Isoprene Epoxydiols-Derived Secondary Organic Aerosol (IEPOX-SOA) Against OH Oxidation and Evaporation, in preparation, 2016.

Huffman, J. A., Ziemann, P. J., Jayne, J. T., Worsnop, D. R., and Jimenez, J. L.: Development and Characterization of a FastStepping/Scanning Thermodenuder for Chemically-Resolved Aerosol Volatility Measurements, Aerosol Sci. Technol., 42, 395-407, doi:10.1080/02786820802104981, 2008.

Hunter, J. F., Day, D. A., Yatavelli, R. N., Chan, A., Kaser, L., Cappellin, L., Hayes, P. L., Palm, B. B., Cross, E. B., Carrasquillo, A., Campuzano-Jost, P., Stark, H., Zhao, Y., Hohaus, T., Smith, J. N., Hansel, A., Karl, T., Goldstein, A. H., Guenther, A., Worsnop, D. R., Thornton, J. A., Heald, C. L., Jimenez, J. L., and Kroll, J. H.: Comprehensive characterization of atmospheric organic carbon at a forested site, submitted, 2016.

IPCC: Climate Change 2013: The Physical Science Basis. Contribution of Working Group I to the Fifth Assessment Report of the Intergovernmental Panel on Climate Change, edited by: Stocker, T. F., Qin, D., Plattner, G., Tignor, M., Allen, S. K., Bex, V., and Midgley, P. M., Cambridge University Press, Cambridge, UK, New York, NY, USA, 2013.

Jimenez, J. L., Canagaratna, M. R., Donahue, N. M., Prevot, A. S. H., Zhang, Q., Kroll, J. H., DeCarlo, P. F., Allan, J. D., Coe, H., Ng, N. L., Aiken, A. C., Docherty, K. S., Ulbrich, I. M., Grieshop, A. P., Robinson, A. L., Duplissy, J., Smith, J. D., Wilson, K. R., Lanz, V. A., Hueglin, C., Sun, Y. L., Tian, J., Laaksonen, A., Raatikainen, T., Rautiainen, J., Vaattovaara, P., Ehn,
M., Kulmala, M., Tomlinson, J. M., Collins, D. R., Cubison, M. J., Dunlea, J., Huffman, J. A., Onasch, T. B., Alfarra, M. R., Williams, P. I., Bower, K., Kondo, Y., Schneider, J., Drewnick, F., Borrmann, S., Weimer, S., Demerjian, K., Salcedo, D., Cottrell, L., Griffin, R., Takami, A., Miyoshi, T., Hatakeyama, S., Shimono, A., Sun, J. Y., Zhang, Y. M., Dzepina, K., Kimmel, J. R., Sueper, D., Jayne, J. T., Herndon, S. C., Trimborn, A. M., Williams, L. R., Wood, E. C., Middlebrook, A. M., Kolb, C. E., Baltensperger, U., and Worsnop, D. R.: Evolution of Organic Aerosols in the Atmosphere, Science, 326, 1525-1529, doi:10.1126/science.1180353, 2009.

Julin, J., Winkler, P. M. P., Donahue, N. M., Wagner, P. E., and Riipinen, I.: Near-unity mass accommodation coefficient of organic molecules of varying structure, Environ. Sci. Technol., 48, 12083-12089, doi:10.1021/es501816h, 2014.

Kang, E., Root, M. J., Toohey, D. W., and Brune, W. H.: Introducing the concept of Potential Aerosol Mass (PAM), Atmos. Chem. Phys., 7, 5727-5744, doi:10.5194/acp-7-5727-2007, 2007.

Kang, E., Toohey, D. W., and Brune, W. H.: Dependence of SOA oxidation on organic aerosol mass concentration and $\mathrm{OH}$ exposure: experimental PAM chamber studies, Atmos. Chem. Phys., 11, 1837-1852, doi:10.5194/acp-11-1837-2011, 2011.

Karl, T., Hansel, A., Cappellin, L., Kaser, L., Herdlinger-Blatt, I., and Jud, W.: Selective measurements of isoprene and 2methyl-3-buten-2-ol based on $\mathrm{NO}^{-1}+$ ionization mass spectrometry, Atmos. Chem. Phys., 12, 11877-11884, doi:10.5194/acp12-11877-2012, 2012.

Kaser, L., Karl, T., Schnitzhofer, R., Graus, M., Herdlinger-Blatt, I. S., DiGangi, J. P., Sive, B., Turnipseed, A., Hornbrook, R. S., Zheng, W., Flocke, F. M., Guenther, A., Keutsch, F. N., Apel, E., and Hansel, A.: Comparison of different real time VOC measurement techniques in a ponderosa pine forest, Atmos. Chem. Phys., 13, 2893-2906, doi:10.5194/acp-13-2893-2013, 2013 a.

Kaser, L., Karl, T., Guenther, A., Graus, M., Schnitzhofer, R., Turnipseed, A., Fischer, L., Harley, P., Madronich, M., Gochis, D., Keutsch, F. N., and Hansel, A.: Undisturbed and disturbed above canopy ponderosa pine emissions: PTR-TOF-MS measurements and MEGAN 2.1 model results, Atmos. Chem. Phys., 13, 11935-11947, doi:10.5194/acp-13-11935-2013, 2013b.

Keller, A. and Burtscher, H.: A continuous photo-oxidation flow reactor for a defined measurement of the SOA formation potential of wood burning emissions, J. Aerosol Sci., 49, 9-20, doi:10.1016/j.jaerosci.2012.02.007, 2012.

Kim, S., Karl, T., Guenther, A., Tyndall, G., Orlando, J., Harley, P., Rasmussen, R., and Apel, E.: Emissions and ambient distributions of Biogenic Volatile Organic Compounds (BVOC) in a ponderosa pine ecosystem: interpretation of PTR-MS mass spectra, Atmos. Chem. Phys., 10, 1759-1771, doi:10.5194/acp-101759-2010, 2010.

Kim, S., Wolfe, G. M., Mauldin, L., Cantrell, C., Guenther, A., Karl, T., Turnipseed, A., Greenberg, J., Hall, S. R., Ullmann, K., Apel, E., Hornbrook, R., Kajii, Y., Nakashima, Y., Keutsch, F. N., DiGangi, J. P., Henry, S. B., Kaser, L., Schnitzhofer, R., Graus, M., Hansel, A., Zheng, W., and Flocke, F. F.: Evaluation of $\mathrm{HO}_{x}$ sources and cycling using measurement-constrained model calculations in a 2-methyl-3-butene-2-ol (MBO) and monoterpene (MT) dominated ecosystem, Atmos. Chem. Phys., 13, 20312044, doi:10.5194/acp-13-2031-2013, 2013. 
Kirkby, J., Curtius, J., Almeida, J., Dunne, E., Duplissy, J., Ehrhart, S., Franchin, A., Gagné, S., Ickes, L., Kürten, A., Kupc, A., Metzger, A., Riccobono, F., Rondo, L., Schobesberger, S., Tsagkogeorgas, G., Wimmer, D., Amorim, A., Bianchi, F., Breitenlechner, M., David, A., Dommen, J., Downard, A., Ehn, M., Flagan, R. C., Haider, S., Hansel, A., Hauser, D., Jud, W., Junninen, H., Kreissl, F., Kvashin, A., Laaksonen, A., Lehtipalo, K., Lima, J., Lovejoy, E. R., Makhmutov, V., Mathot, S., Mikkilä, J., Minginette, P., Mogo, S., Nieminen, T., Onnela, A., Pereira, P., Petäjä, T., Schnitzhofer, R., Seinfeld, J. H., Sipilä, M., Stozhkov, Y., Stratmann, F., Tomé, A., Vanhanen, J., Viisanen, Y., Vrtala, A., Wagner, P. E., Walther, H., Weingartner, E., Wex, H., Winkler, P. M., Carslaw, K. S., Worsnop, D. R., Baltensperger, U., and Kulmala, M.: Role of sulphuric acid, ammonia and galactic cosmic rays in atmospheric aerosol nucleation, Nature, 476, 429-433, doi:10.1038/nature10343, 2011.

Knote, C., Hodzic, A., and Jimenez, J. L.: The effect of dry and wet deposition of condensable vapors on secondary organic aerosols concentrations over the continental US, Atmos. Chem. Phys., 15, 1-18, doi:10.5194/acp-15-1-2015, 2015.

Krechmer, J. E., Coggon, M. M., Massoli, P., Nguyen, T. B., Crounse, J. D., Hu, W., Day, D. A., Tyndall, G. S., Henze, D. K., Rivera-Rios, J. C., Nowak, J. B., Kimmel, J. R., Mauldin, R. L., Stark, H., Jayne, J. T., Sipilä, M., Junninen, H., Clair, J. M. St., Zhang, X., Feiner, P. A., Zhang, L., Miller, D. O., Brune, W. H., Keutsch, F. N., Wennberg, P. O., Seinfeld, J. H., Worsnop, D. R., Jimenez, J. L., and Canagaratna, M. R.: Formation of Low Volatility Organic Compounds and Secondary Organic Aerosol from Isoprene Hydroxyhydroperoxide Low-NO Oxidation, Environ. Sci. Technol., 49, 10330-10339, doi:10.1021/acs.est.5b02031, 2015.

Kulmala, M. and Wagner, P. E.: Mass accommodation and uptake coefficients - a quantitative comparison, J. Aerosol Sci., 32, 833841, doi:10.1016/S0021-8502(00)00116-6, 2001.

Kuwata, M., Zorn, S. R., and Martin, S. T.: Using elemental ratios to predict the density of organic material composed of carbon, hydrogen, and oxygen., Environ. Sci. Technol., 46, 787-94, doi:10.1021/es202525q, 2012.

Lambe, A. T., Ahern, A. T., Williams, L. R., Slowik, J. G., Wong, J. P. S., Abbatt, J. P. D., Brune, W. H., Ng, N. L., Wright, J. P., Croasdale, D. R., Worsnop, D. R., Davidovits, P., and Onasch, T. B.: Characterization of aerosol photooxidation flow reactors: heterogeneous oxidation, secondary organic aerosol formation and cloud condensation nuclei activity measurements, Atmos. Meas. Tech., 4, 445-461, doi:10.5194/amt-4-445-2011, $2011 \mathrm{a}$.

Lambe, A. T., Onasch, T. B., Massoli, P., Croasdale, D. R., Wright, J. P., Ahern, A. T., Williams, L. R., Worsnop, D. R., Brune, W. H., and Davidovits, P.: Laboratory studies of the chemical composition and cloud condensation nuclei $(\mathrm{CCN})$ activity of secondary organic aerosol (SOA) and oxidized primary organic aerosol (OPOA), Atmos. Chem. Phys., 11, 8913-8928, doi:10.5194/acp11-8913-2011, 2011b.

Lambe, A. T., Chhabra, P. S., Onasch, T. B., Brune, W. H., Hunter, J. F., Kroll, J. H., Cummings, M. J., Brogan, J. F., Parmar, Y., Worsnop, D. R., Kolb, C. E., and Davidovits, P.: Effect of oxidant concentration, exposure time, and seed particles on secondary organic aerosol chemical composition and yield, Atmos. Chem. Phys., 15, 3063-3075, doi:10.5194/acp-15-3063-2015, 2015.
Lane, T. E., Donahue, N. M., and Pandis, S. N.: Effect of $\mathrm{NO}_{x}$ on secondary organic aerosol concentrations, Environ. Sci. Technol., 42, 6022-6027, doi:10.1021/Es703225a, 2008.

Lee, A., Goldstein, A. H., Kroll, J. H., Ng, N. L., Varutbangkul, V., Flagan, R. C., and Seinfeld, J. H.: Gas-phase products and secondary aerosol yields from the photooxidation of 16 different terpenes, J. Geophys. Res., 111, D17305, doi:10.1029/2006JD007050, 2006.

Levin, E. J. T., Prenni, A. J., Palm, B. B., Day, D. A., CampuzanoJost, P., Winkler, P. M., Kreidenweis, S. M., DeMott, P. J., Jimenez, J. L., and Smith, J. N.: Size-resolved aerosol composition and its link to hygroscopicity at a forested site in Colorado, Atmos. Chem. Phys., 14, 2657-2667, doi:10.5194/acp-14-26572014, 2014.

Li, R., Palm, B. B., Ortega, A. M., Hlywiak, J., Hu, W., Peng, Z., Day, D. A., Knote, C., Brune, W. H., de Gouw, J. A., and Jimenez, J. L.: Modeling the Radical Chemistry in an Oxidation Flow Reactor: Radical Formation and Recycling, Sensitivities, and the $\mathrm{OH}$ Exposure Estimation Equation, J. Phys. Chem. A, 119, 4418-4432, doi:10.1021/jp509534k, 2015.

Lim, Y. B. and Ziemann, P. J.: Effects of Molecular Structure on Aerosol Yields from $\mathrm{OH}$ Radical-Initiated Reactions of Linear, Branched, and Cyclic Alkanes in the Presence of $\mathrm{NO}_{x}$, Environ. Sci. Technol., 43, 2328-2334, doi:10.1021/es803389s, 2009.

Lim, Y. B., Tan, Y., Perri, M. J., Seitzinger, S. P., and Turpin, B. J.: Aqueous chemistry and its role in secondary organic aerosol (SOA) formation, Atmos. Chem. Phys., 10, 1052110539, doi:10.5194/acp-10-10521-2010, 2010.

Lopez-Hilfiker, F. D., Mohr, C., D’Ambro, E. L., Lutz, A., Riedel, T. P., Gaston, C. J., Iyer, S., Zhang, Z., Gold, A., Surratt, J. D., Lee, B. H., Kurten, T., Hu, W. W., Jimenez, J., Hallquist, M. and Thornton, J. A.: Molecular Composition and Volatility of Organic Aerosol in the Southeastern U.S.: Implications for IEPOX Derived SOA, Environ. Sci. Technol., 50, 2200-2209, doi:10.1021/acs.est.5b04769, 2016.

Mao, J., Ren, X., Brune, W. H., Olson, J. R., Crawford, J. H., Fried, A., Huey, L. G., Cohen, R. C., Heikes, B., Singh, H. B., Blake, D. R., Sachse, G. W., Diskin, G. S., Hall, S. R., and Shetter, R. E.: Airborne measurement of OH reactivity during INTEX-B, Atmos. Chem. Phys., 9, 163-173, doi:10.5194/acp-9-163-2009, 2009.

Matsunaga, A. and Ziemann, P. J.: Gas-Wall Partitioning of Organic Compounds in a Teflon Film Chamber and Potential Effects on Reaction Product and Aerosol Yield Measurements, Aerosol Sci Technol., 44, 881-892, doi:10.1080/02786826.2010.501044, 2010.

McMurry, P. H. and Grosjean, D.: Gas and aerosol wall losses in Teflon film smog chambers, Environ. Sci. Technol., 19, 11761182, doi:10.1021/es00142a006, 1985.

Miracolo, M. A., Presto, A. A., Lambe, A. T., Hennigan, C. J., Donahue, N. M., Kroll, J. H., Worsnop, D. R., and Robinson, A. L.: Photo-Oxidation of Low-Volatility Organics Found in Motor Vehicle Emissions: Production and Chemical Evolution of Organic Aerosol Mass, Environ. Sci. Technol., 44, 1638-1643, doi:10.1021/es902635c, 2010.

Misztal, P. K., Hewitt, C. N., Wildt, J., Blande, J. D., Eller, A. S. D., Fares, S., Gentner, D. R., Gilman, J. B., Graus, M., Greenberg, J., Guenther, A. B., Hansel, A., Harley, P., Huang, M., Jardine, K., Karl, T., Kaser, L., Keutsch, F. N., Kiendler-Scharr, A., Kleist, 
E., Lerner, B. M., Li, T., Mak, J., Nölscher, A. C., Schnitzhofer, R., Sinha, V., Thornton, B., Warneke, C., Wegener, F., Werner, C., Williams, J., Worton, D. R., Yassaa, N., and Goldstein, A. H.: Atmospheric benzenoid emissions from plants rival those from fossil fuels, Sci. Rep., 5, 12064, doi:10.1038/srep12064, 2015.

Murphy, D. M., Cziczo, D. J., Froyd, K. D., Hudson, P. K., Matthew, B. M., Middlebrook, A. M., Peltier, R. E., Sullivan, A., Thomson, D. S., and Weber, R. J.: Single-particle mass spectrometry of tropospheric aerosol particles, J. Geophys. Res., 111, D23S32, doi:10.1029/2006jd007340, 2006.

Myhre, G., Shindell, D., Bréon, F.-M., Collins, W., Fuglestvedt, J., Huang, J., Koch, D., Lamarque, J.-F., Lee, D., Mendoza, B., Nakajima, T., Robock, A., Stephens, G., Takemura, T., and Zhang, H.: Anthropogenic and Natural Radiative Forcing, in Climate Change 2013: The Physical Science Basis, Contribution of Working Group I to the Fifth Assessment Report of the Intergovernmental Panel on Climate Change, edited by: Stocker, T. F., Qin, D., Plattner, G.-K., Tignor, M., Allen, S. K., Boschung, J., Nauels, A., Xia, Y., Bex, V., and Midgley, P. M., Cambridge University Press, Cambridge, UK, New York, NY, USA, 659-740, 2013.

Nakashima, Y., Kato, S., Greenberg, J., Harley, P., Karl, T., Turnipseed, A., Apel, E., Guenther, A., Smith, J., and Kajii, Y.: Total $\mathrm{OH}$ reactivity measurements in ambient air in a southern Rocky mountain ponderosa pine forest during BEACHON-SRM08 summer campaign, Atmos. Environ., 85, 18, doi:10.1016/j.atmosenv.2013.11.042, 2014.

Ng, N. L., Chhabra, P. S., Chan, A. W. H., Surratt, J. D., Kroll, J. H., Kwan, A. J., McCabe, D. C., Wennberg, P. O., Sorooshian, A., Murphy, S. M., Dalleska, N. F., Flagan, R. C., and Seinfeld, J. H.: Effect of $\mathrm{NO}_{x}$ level on secondary organic aerosol (SOA) formation from the photooxidation of terpenes, Atmos. Chem. Phys., 7, 5159-5174, doi:10.5194/acp-7-5159-2007, 2007.

Nguyen, T. B., Crounse, J. D., Teng, A. P., St. Clair, J. M., Paulot, F., Wolfe, G. M., and Wennberg, P. O.: Rapid deposition of oxidized biogenic compounds to a temperate forest, P. Natl. Acad. Sci. USA, 112, E392-E401, doi:10.1073/pnas.1418702112, 2015.

Ortega, A. M., Day, D. A., Cubison, M. J., Brune, W. H., Bon, D., de Gouw, J. A., and Jimenez, J. L.: Secondary organic aerosol formation and primary organic aerosol oxidation from biomass-burning smoke in a flow reactor during FLAME-3, Atmos. Chem. Phys., 13, 11551-11571, doi:10.5194/acp-1311551-2013, 2013.

Ortega, A. M., Hayes, P. L., Peng, Z., Palm, B. B., Hu, W., Day, D. A., Li, R., Cubison, M. J., Brune, W. H., Graus, M., Warneke, C., Gilman, J. B., Kuster, W. C., de Gouw, J. A., and Jimenez, J. L.: Real-time measurements of secondary organic aerosol formation and aging from ambient air in an oxidation flow reactor in the Los Angeles area, Atmos. Chem. Phys. Discuss., 15, 21907-21958, doi:10.5194/acpd-15-21907-2015, 2015.

Ortega, J., Turnipseed, A., Guenther, A. B., Karl, T. G., Day, D. A., Gochis, D., Huffman, J. A., Prenni, A. J., Levin, E. J. T., Kreidenweis, S. M., DeMott, P. J., Tobo, Y., Patton, E. G., Hodzic, A., Cui, Y. Y., Harley, P. C., Hornbrook, R. S., Apel, E. C., Monson, R. K., Eller, A. S. D., Greenberg, J. P., Barth, M. C., CampuzanoJost, P., Palm, B. B., Jimenez, J. L., Aiken, A. C., Dubey, M. K., Geron, C., Offenberg, J., Ryan, M. G., Fornwalt, P. J., Pryor, S. C., Keutsch, F. N., DiGangi, J. P., Chan, A. W. H., Goldstein, A. H., Wolfe, G. M., Kim, S., Kaser, L., Schnitzhofer, R., Hansel,
A., Cantrell, C. A., Mauldin, R. L., and Smith, J. N.: Overview of the Manitou Experimental Forest Observatory: site description and selected science results from 2008 to 2013, Atmos. Chem. Phys., 14, 6345-6367, doi:10.5194/acp-14-6345-2014, 2014.

Pankow, J. F.: An Absorption-Model of Gas-Particle Partitioning of Organic-Compounds in the Atmosphere, Atmos. Environ., 28, 185-188, doi:10.1016/1352-2310(94)90093-0, 1994.

Paulot, F., Crounse, J. D., Kjaergaard, H. G., Kürten, A., St. Clair, J. M., Seinfeld, J. H., and Wennberg, P. O.: Unexpected Epoxide Formation in the Gas-Phase Photooxidation of Isoprene, Science, 325, 730-733, doi:10.1126/science.1172910, 2009.

Peng, Z., Day, D. A., Stark, H., Li, R., Lee-Taylor, J., Palm, B. B., Brune, W. H., and Jimenez, J. L.: $\mathrm{HO}_{x}$ radical chemistry in oxidation flow reactors with low-pressure mercury lamps systematically examined by modeling, Atmos. Meas. Tech., 8, 4863-4890, doi:10.5194/amt-8-4863-2015, 2015a.

Peng, Z., Day, D. A., Ortega, A. M., Palm, B. B., Hu, W. W., Stark, H., Li, R., Tsigaridis, K., Brune, W. H., and Jimenez, J. L.: Non$\mathrm{OH}$ chemistry in oxidation flow reactors for the study of atmospheric chemistry systematically examined by modeling, Atmos. Chem. Phys. Discuss., 15, 23543-23586, doi:10.5194/acpd-1523543-2015, 2015b.

Petters, M. D. and Kreidenweis, S. M.: A single parameter representation of hygroscopic growth and cloud condensation nucleus activity, Atmos. Chem. Phys., 7, 1961-1971, doi:10.5194/acp-71961-2007, 2007.

Pierce, J. R., Engelhart, G. J., Hildebrandt, L., Weitkamp, E. A., Pathak, R. K., Donahue, N. M., Robinson, A. L., Adams, P. J., and Pandis, S. N.: Constraining Particle Evolution from Wall Losses, Coagulation, and Condensation-Evaporation in SmogChamber Experiments: Optimal Estimation Based on Size Distribution Measurements, Aerosol Sci. Technol., 42, 1001-1015, doi:10.1080/02786820802389251, 2008.

Pirjola, L., Kulmala, M., Wilck, M., Bischoff, A., Stratmann, F., and Otto, E.: Formation Of Sulphuric Acid Aerosols And Cloud Condensation Nuclei: An Expression For Significant Nucleation And Model Comparison, J. Aerosol Sci., 30, 1079-1094, doi:10.1016/S0021-8502(98)00776-9, 1999.

Pope, C. A. and Dockery, D. W.: Health Effects of Fine Particulate Air Pollution: Lines that Connect, J. Air Waste Manage. Assoc., 56, 709-742, doi:10.1080/10473289.2006.10464485, 2006.

Pöschl, U., Canagaratna, M., Jayne, J. T., Molina, L. T., Worsnop, D. R., Kolb, C. E., and Molina, M. J.: Mass Accommodation Coefficient of $\mathrm{H}_{2} \mathrm{SO}_{4}$ Vapor on Aqueous Sulfuric Acid Surfaces and Gaseous Diffusion Coefficient of $\mathrm{H}_{2} \mathrm{SO}_{4}$ in $\mathrm{N}_{2} / \mathrm{H}_{2} \mathrm{O}$, J. Phys. Chem. A, 102, 10082-10089, doi:10.1021/jp982809s, 1998.

Presto, A. A., Miracolo, M. A., Donahue, N. M., and Robinson, A. L.: Secondary Organic Aerosol Formation from High-NO Photo-Oxidation of Low Volatility Precursors: N-Alkanes, Environ. Sci. Technol., 44, 2029-2034, doi:10.1021/es903712r, 2010.

Robinson, A. L., Donahue, N. M., Shrivastava, M. K., Weitkamp, E. A., Sage, A. M., Grieshop, A. P., Lane, T. E., Pierce, J. R., and Pandis, S. N.: Rethinking Organic Aerosols: Semivolatile Emissions and Photochemical Aging, Science, 315, 1259-1262, doi:10.1126/science.1133061, 2007.

Salcedo, D., Onasch, T. B., Dzepina, K., Canagaratna, M. R., Zhang, Q., Huffman, J. A., DeCarlo, P. F., Jayne, J. T., Mortimer, P., Worsnop, D. R., Kolb, C. E., Johnson, K. S., Zuberi, B., Marr, L. C., Volkamer, R., Molina, L. T., Molina, M. J., Car- 
denas, B., Bernabé, R. M., Márquez, C., Gaffney, J. S., Marley, N. A., Laskin, A., Shutthanandan, V., Xie, Y., Brune, W., Lesher, R., Shirley, T., and Jimenez, J. L.: Characterization of ambient aerosols in Mexico City during the MCMA-2003 campaign with Aerosol Mass Spectrometry: results from the CENICA Supersite, Atmos. Chem. Phys., 6, 925-946, doi:10.5194/acp-6-925-2006, 2006.

Sander, S. P., Abbatt, J. P. D., Barker, J. R., Burkholder, J. B., Friedl, R. R., Golden, D. M., Huie, R. E., Kolb, C. E., Kurylo, M. J., Moortgat, G. K., Orkin, V. L., and Wine, P. H.: Chemical Kinetics and Photochemical Data for Use in Atmospheric Studies Evaluation Number 17, JPL Publ. 10-6, Jet Propulsion Laboratory, California Institute of Technology, Pasadena, CA, USA, 2011.

Seinfeld, J. H. and Pandis, S. N.: Atmospheric chemistry and physics: from air pollution to climate change, 2nd ed., John Wiley \& Sons, Inc., Hoboken, New Jersey, USA, 2006.

Slowik, J. G., Stroud, C., Bottenheim, J. W., Brickell, P. C., Chang, R. Y.-W., Liggio, J., Makar, P. A., Martin, R. V., Moran, M. D., Shantz, N. C., Sjostedt, S. J., van Donkelaar, A., Vlasenko, A., Wiebe, H. A., Xia, A. G., Zhang, J., Leaitch, W. R., and Abbatt, J. P. D.: Characterization of a large biogenic secondary organic aerosol event from eastern Canadian forests, Atmos. Chem. Phys., 10, 2825-2845, doi:10.5194/acp-10-2825-2010, 2010.

Smith, J. D., Kroll, J. H., Cappa, C. D., Che, D. L., Liu, C. L., Ahmed, M., Leone, S. R., Worsnop, D. R., and Wilson, K. R.: The heterogeneous reaction of hydroxyl radicals with submicron squalane particles: a model system for understanding the oxidative aging of ambient aerosols, Atmos. Chem. Phys., 9, 3209-3222, doi:10.5194/acp-9-3209-2009, 2009.

Surratt, J. D., Chan, A. W. H., Eddingsaas, N. C., Chan, M., Loza, C. L., Kwan, A. J., Hersey, S. P., Flagan, R. C., Wennberg, P. O., and Seinfeld, J. H.: Reactive intermediates revealed in secondary organic aerosol formation from isoprene., P. Natl. Acad. Sci. USA, 107, 6640-6645, doi:10.1073/pnas.0911114107, 2010.

Tanaka, P. L., Allen, D. T., and Mullins, C. B.: An environmental chamber investigation of chlorine-enhanced ozone formation in Houston, Texas, J. Geophys. Res., 108, 4576, doi:10.1029/2002JD003314, 2003.

Tang, M. J., Shiraiwa, M., Pöschl, U., Cox, R. A., and Kalberer, M.: Compilation and evaluation of gas phase diffusion coefficients of reactive trace gases in the atmosphere: Volume 2. Diffusivities of organic compounds, pressure-normalised mean free paths, and average Knudsen numbers for gas uptake calculations, Atmos. Chem. Phys., 15, 5585-5598, doi:10.5194/acp-15-55852015, 2015.

Tkacik, D. S., Presto, A. A., Donahue, N. M., and Robinson, A. L.: Secondary organic aerosol formation from intermediate-volatility organic compounds: cyclic, linear, and branched alkanes., Environ. Sci. Technol., 46, 8773-8781, doi:10.1021/es301112c, 2012.

Tkacik, D. S., Lambe, A. T., Jathar, S., Li, X., Presto, A. A., Zhao, Y., Blake, D., Meinardi, S., Jayne, J. T., Croteau, P. L., and Robinson, A. L.: Secondary Organic Aerosol Formation from in-Use Motor Vehicle Emissions Using a Potential Aerosol Mass Reactor, Environ. Sci. Technol., 48, 11235-11242, doi:10.1021/es502239v, 2014.

Tsigaridis, K., Daskalakis, N., Kanakidou, M., Adams, P. J., Artaxo, P., Bahadur, R., Balkanski, Y., Bauer, S. E., Bellouin, N., Benedetti, A., Bergman, T., Berntsen, T. K., Beukes, J. P., Bian,
H., Carslaw, K. S., Chin, M., Curci, G., Diehl, T., Easter, R. C., Ghan, S. J., Gong, S. L., Hodzic, A., Hoyle, C. R., Iversen, T., Jathar, S., Jimenez, J. L., Kaiser, J. W., Kirkevåg, A., Koch, D., Kokkola, H., Lee, Y. H, Lin, G., Liu, X., Luo, G., Ma, X., Mann, G. W., Mihalopoulos, N., Morcrette, J.-J., Müller, J.-F., Myhre, G., Myriokefalitakis, S., Ng, N. L., O’Donnell, D., Penner, J. E., Pozzoli, L., Pringle, K. J., Russell, L. M., Schulz, M., Sciare, J., Seland, Ø., Shindell, D. T., Sillman, S., Skeie, R. B., Spracklen, D., Stavrakou, T., Steenrod, S. D., Takemura, T., Tiitta, P., Tilmes, S., Tost, H., van Noije, T., van Zyl, P. G., von Salzen, K., Yu, F., Wang, Z., Wang, Z., Zaveri, R. A., Zhang, H., Zhang, K., Zhang, Q., and Zhang, X.: The AeroCom evaluation and intercomparison of organic aerosol in global models, Atmos. Chem. Phys., 14, 10845-10895, doi:10.5194/acp-1410845-2014, 2014.

Tsimpidi, A. P., Karydis, V. A., Zavala, M., Lei, W., Molina, L., Ulbrich, I. M., Jimenez, J. L., and Pandis, S. N.: Evaluation of the volatility basis-set approach for the simulation of organic aerosol formation in the Mexico City metropolitan area, Atmos. Chem. Phys., 10, 525-546, doi:10.5194/acp-10-525-2010, 2010.

Tunved, P., Hansson, H.-C., Kerminen, V.-M., Ström, J., Maso, M. D., Lihavainen, H., Viisanen, Y., Aalto, P. P., Komppula, M., and Kulmala, M.: High natural aerosol loading over boreal forests., Science, 312, 261-263, doi:10.1126/science.1123052, 2006.

Vaden, T. D., Imre, D., Beranek, J., Shrivastava, M., and Zelenyuk, A.: Evaporation kinetics and phase of laboratory and ambient secondary organic aerosol, P. Natl. Acad. Sci. USA, 108, 2190 2195, doi:10.1073/pnas.1013391108, 2011.

Volkamer, R., Jimenez, J. L., San Martini, F., Dzepina, K., Zhang, Q., Salcedo, D., Molina, L. T., Worsnop, D. R., and Molina, M. J.: Secondary organic aerosol formation from anthropogenic air pollution: Rapid and higher than expected, Geophys. Res. Lett., 33, L17811, doi:10.1029/2006g1026899, 2006.

Wolfe, G. M., Cantrell, C., Kim, S., Mauldin III, R. L., Karl, T., Harley, P., Turnipseed, A., Zheng, W., Flocke, F., Apel, E. C., Hornbrook, R. S., Hall, S. R., Ullmann, K., Henry, S. B., DiGangi, J. P., Boyle, E. S., Kaser, L., Schnitzhofer, R., Hansel, A., Graus, M., Nakashima, Y., Kajii, Y., Guenther, A., and Keutsch, F. N.: Missing peroxy radical sources within a summertime ponderosa pine forest, Atmos. Chem. Phys., 14, 4715-4732, doi:10.5194/acp-14-4715-2014, 2014.

Wyche, K. P., Ryan, A. C., Hewitt, C. N., Alfarra, M. R., McFiggans, G., Carr, T., Monks, P. S., Smallbone, K. L., Capes, G., Hamilton, J. F., Pugh, T. A. M., and MacKenzie, A. R.: Emissions of biogenic volatile organic compounds and subsequent photochemical production of secondary organic aerosol in mesocosm studies of temperate and tropical plant species, Atmos. Chem. Phys., 14, 12781-12801, doi:10.5194/acp-14-12781-2014, 2014

Yatavelli, R. L. N., Stark, H., Thompson, S. L., Kimmel, J. R., Cubison, M. J., Day, D. A., Campuzano-Jost, P., Palm, B. B., Hodzic, A., Thornton, J. A., Jayne, J. T., Worsnop, D. R., and Jimenez, J. L.: Semicontinuous measurements of gas-particle partitioning of organic acids in a ponderosa pine forest using a MOVI-HRToFCIMS, Atmos. Chem. Phys., 14, 1527-1546, doi:10.5194/acp14-1527-2014, 2014.

Zhang, H., Worton, D. R., Lewandowski, M., Ortega, J., Rubitschun, C. L., Park, J.-H., Kristensen, K., Campuzano-Jost, P., Day, D. A., Jimenez, J. L., Jaoui, M., Offenberg, J. H., Kleindienst, T. E., Gilman, J., Kuster, W. C., de Gouw, J., Park, C., 
Schade, G. W., Frossard, A. A., Russell, L., Kaser, L., Jud, W., Hansel, A., Cappellin, L., Karl, T., Glasius, M., Guenther, A., Goldstein, A. H., Seinfeld, J. H., Gold, A., Kamens, R. M., and Surratt, J. D.: Organosulfates as Tracers for Secondary Organic Aerosol (SOA) Formation from 2-Methyl-3-Buten-2-ol (MBO) in the Atmosphere, Environ. Sci. Technol., 46, 94379446, doi:10.1021/es301648z, 2012.

Zhang, Q., Jimenez, J. L., Canagaratna, M. R., Allan, J. D., Coe, H., Ulbrich, I., Alfarra, M. R., Takami, A., Middlebrook, A. M., Sun, Y. L., Dzepina, K., Dunlea, E., Docherty, K., DeCarlo, P. F., Salcedo, D., Onasch, T., Jayne, J. T., Miyoshi, T., Shimono, A., Hatakeyama, S., Takegawa, N., Kondo, Y., Schneider, J., Drewnick, F., Borrmann, S., Weimer, S., Demerjian, K., Williams, P., Bower, K., Bahreini, R., Cottrell, L., Griffin, R. J., Rautiainen, J., Sun, J. Y., Zhang, Y. M., and Worsnop, D. R.: Ubiquity and dominance of oxygenated species in organic aerosols in anthropogenically-influenced Northern Hemisphere midlatitudes, Geophys. Res. Lett., 34, L13801, doi:10.1029/2007GL029979, 2007.
Zhang, X., Cappa, C. D., Jathar, S. H., McVay, R. C., Ensberg, J. J., Kleeman, M. J., and Seinfeld, J. H.: Influence of vapor wall loss in laboratory chambers on yields of secondary organic aerosol., P. Natl. Acad. Sci. USA, 111, 5802-5807, doi:10.1073/pnas.1404727111, 2014.

Zhao, Y., Hennigan, C. J., May, A. A., Tkacik, D. S., de Gouw, J. A., Gilman, J. B., Kuster, W. C., Borbon, A., and Robinson, A. L.: Intermediate-volatility organic compounds: a large source of secondary organic aerosol., Environ. Sci. Technol., 48, 1374350, doi:10.1021/es5035188, 2014.

Ziemann, P. J. and Atkinson, R.: Kinetics, products, and mechanisms of secondary organic aerosol formation, Chem. Soc. Rev., 41, 6582, doi:10.1039/c2cs35122f, 2012. 